\title{
Exploration of microRNAs in porcine milk exosomes
}

\author{
Ting Chen ${ }^{\dagger}$, Qian-Yun Xi ${ }^{\dagger}$, Rui-Song Ye, Xiao Cheng, Qi-En Qi, Song-Bo Wang, Gang Shu, Li-Na Wang,
} Xiao-Tong Zhu, Qing-Yan Jiang and Yong-Liang Zhang ${ }^{*}$

\begin{abstract}
Background: Breast milk contains complex nutrients and facilitates the maturation of various biological systems in infants. Exosomes, membranous vesicles of endocytic origin found in different body fluids such as milk, can mediate intercellular communication. We hypothesized that microRNAs (miRNAs), a class of non-coding small RNAs of 18-25 nt which are known to be packaged in exosomes of human, bovine and porcine milk, may play important roles in the development of piglets.
\end{abstract}

Results: In this study, exosomes of approximately $100 \mathrm{~nm}$ in diameter were isolated from porcine milk through serial centrifugation and ultracentrifugation procedures. Total RNA was extracted from exosomes, and $5 \mathrm{~S}$ ribosomal RNA was found to be the major RNA component. Solexa sequencing showed a total of 491 miRNAs, including 176 known miRNAs and 315 novel mature miRNAs (representing 366 pre-miRNAs), which were distributed among 30 clusters and 35 families, and two predicted novel miRNAs were verified targeting 3'UTR of IGF-1R by luciferase assay. Interestingly, we observed that three miRNAs (ssc-let-7e, ssc-miR-27a, and ssc-miR-30a) could be generated from miRNA-offset RNAs (moRNAs). The top 10 miRNAs accounted for $74.5 \%$ (67,154 counts) of total counts, which were predicted to target 2,333 genes by RNAhybrid software. Gene Ontology and Kyoto Encyclopedia of Genes and Genomes (KEGG) pathway analyses using DAVID bioinformatics resources indicated that the identified miRNAs targeted genes enriched in transcription, immunity and metabolism processes, and 14 of the top 20 miRNAs possibly participate in regulation of the IgA immune network.

Conclusions: Our findings suggest that porcine milk exosomes contain a large number of miRNAs, which potentially play an important role in information transfer from sow milk to piglets. The predicted miRNAs of porcine milk exosomes in this study provide a basis for future biochemical and biophysical function studies.

Keywords: Porcine milk exosomes, Solexa sequencing, miRNA

\section{Background}

Milk, as the sole source of nutrition for infants, contains a potent mixture of diverse components such as milk fat globules (MFG) [1], immune competent cells and soluble proteins, for instance IgA, cytokines and antimicrobial peptides [2], which can provide protection against infections in newborns [3]. In addition, breast milk may have a role in tolerance induction [1] and may protect infants from developing allergies [4].

\footnotetext{
* Correspondence: Zhangyl@scau.edu.cn

${ }^{\dagger}$ Equal contributors

Guandong Provincial Key Lab of Agro-Animal Genomics And Molecular Breeding, College of Animal Science, ALLTECH-SCAU Animal Nutrition Control Research Alliance, National Engineering Research Center For Breeding Swine Industry, South China Agricultural University, Guangzhou 510642, China
}

Exosomes are small $(30-100 \mathrm{~nm})$ membrane vesicles of endocytic origin that are released into the extracellular environment upon fusion of multivesicular bodies (MVB) with the plasma membrane [5]. Many cells have the capacity to release exosomes, including reticulocytes [6], dendritic cells [7], B cells [8], $\mathrm{T}$ cells [9], mast cells [10], epithelial cells [11] and tumor cells [12]. In addition, exosomes have been found in physiological fluids, such as saliva [13,14], plasma [15], urine [16], amniotic fluid [17], malignant ascites [18], bronchoalveolar lavage fluid [19] and synovial fluids [20]. Several studies have suggested that exosomes, which contain proteins, mRNA and microRNA (miRNA), stimulate and transfer surface receptors to target cells [21-23], as well as serve as novel vehicles for genetic exchange between cells

\section{Biomed Central}


[24]. As with other biological fluids, microvesicle-like particles are also present in mouse milk [25] and human milk [26]. Recent published studies have isolated mRNAs and miRNAs from bovine milk-derived microvesicles [27]. One study via deep sequencing technology identified 602 unique miRNAs originating from 452 miRNA precursors (pre-miRNAs) in human breast milk exosomes and found that, out of 87 well-characterized immune-related premiRNAs, 59 (67.82\%) were enriched in breast milk exosomes [28]. Recently, porcine milk was reported to contain 180 pre-miRNAs, including 140 known and 40 novel porcine pre-miRNAs, altogether encoding 237 mature miRNAs [29].

MiRNAs are widespread among eukaryotes and represent key components of a conserved system of RNA-based gene regulation [30-33]. Many studies have demonstrated that miRNAs are key post-transcriptional regulators of gene expression and play important roles in a wide range of physiological and pathological processes [34], including development, differentiation, proliferation and immune responses. It is believed that about $60 \%$ of mammalian genes are regulated by miRNAs [35-39].

Aside from being important farm livestock, pigs are also model animals for medical research. In the present study, we investigated miRNAs in milk exosomes of Landrace pigs in order to provide new information for investigations into the physiological functions of porcine milk.

\section{Methods}

\section{Milk samples}

Porcine milk samples were collected between day 1 to 5 after parturition from healthy lactating Landrace female pigs bred in the breeding farm of the Livestock Research Institute (Guangzhou, China). Milk samples were frozen immediately after milking and were kept at $-80^{\circ} \mathrm{C}$ until use.

\section{Preparation of exosomes from milk}

Porcine milk samples were centrifuged first at 2,000 $\times g$ for $30 \mathrm{~min}$ at $4^{\circ} \mathrm{C}$ to remove MFGs as well as mammary glandderived cells. Defatted samples were then subjected to centrifugations at $4^{\circ} \mathrm{C}$ for $30 \mathrm{~min}$ at $12,000 \times g$ to remove residual MFGs, casein and other debris. Subsequently, from the final supernatant (so-called whey or milk serum), the membrane fraction was prepared by ultracentrifugation at $110,000 \times g$ for $2 \mathrm{~h}$ in an SW41T rotor (Beckman Coulter Instruments, Fullerton, CA) [40].

\section{Transmission electron microscopy (TEM)}

The final fraction obtained as described above was diluted with $0.01 \mathrm{M}$ PBS and ultracentrifuged again to recover microvesicles as pellets. Following fixation in $2 \%$ glutaraldehyde, microvesicles were negatively stained with uranyl acetate and observed by TEM (JEOL JEM2000EX, Tokyo, Japan).

\section{RNA isolation and Solexa sequencing}

Total RNA was isolated from samples collected after ultracentrifugation using Trizol reagent (Invitrogen, Carlsbad, CA) according to the manufacturer's protocol. The quality of RNA was examined by $2 \%$ agarose gel electrophoresis and with a Biophotometer 6131 (Eppendorf, Germany), as well as further confirmed by using a Bioanalyzer (Agilent Technologies, Santa Clara, CA). Small RNAs (18-30 nt) were obtained from the total RNA, 5' and 3' adaptors were ligated to the small RNAs, then the adaptor-ligated RNAs were subsequently transcribed into CDNA by RT-PCR, and the samples were amplified by PCR using primers complementary to the two adaptors. The PCR products were purified and subjected to Solexa sequencing (Illumina, CA) at the Beijing Genomics Institute (BGI, Shenzhen, China).

\section{Sequence data analysis}

The raw reads obtained from Solexa sequencing were processed to obtain clean reads by summarizing data production, evaluating sequencing quality, calculating the length distribution of small RNA reads, removing low quality reads and adaptor sequences as described in previous paper [41]. All the clean reads were aligned against non-coding RNAs from the GenBank and Rfam (11.0) (ftp.sanger.ac.uk/pub/databases/Rfam) database to annotate and classify rRNA, tRNA, snRNA and other ncRNA sequences using tag2 annotation software (developed by BGI). Then the selected sequences were mapped to the pig genome (sscrofa9, www.ensembl.org/Sus_scrofa/) using SOAPv1.11 software [42] to analyze their expression and distribution. Subsequently, the miRNA candidates were further analyzed by miRDeep 2 against all known miRNAs and porcine miRNA precursors (miRBase 20.0). All remaining candidates who did not map to any miRNAs in miRBase 20.0 were considered as potential novel miRNAs. To further identify these potential novel miRNA candidates, software MIREAPv0.2 (http://sourceforge.net/projects/mireap) [43] developed by BGI was used to predict novel miRNA by exploring the secondary structure, the Dicer cleavage site and the minimum free energy of the annotated small RNAs which could be mapped to genome. In briefly, the sequence length should be between 18-26 nt, maximal free energy allowed for a miRNA precursor was $-18 \mathrm{kcal} / \mathrm{mol}$, maximal space between miRNA and miRNA* was $35 \mathrm{nt}$, and flank sequence length of miRNA precursor should be $10 \mathrm{nt}$. Finally, all remaining novel miRNA candidates were further subjected to MiPred (http://www.bioinf.seu.edu.cn/miRNA/) to filter out pseudo-pre-miRNAs. The minimum free energy 
must be $>-20 \mathrm{kcal} / \mathrm{mol}$ or P-value was $>0.05$ [44], and their secondary structures were also checked using the Mfold3.2 software [45]. All data for analysis in this study have been deposited in https://mynotebook.labarchives. com/share/allinchen/MTkuNXwxMzMxMS8xNS0yL1R yZWVOb2RILzE1NzEyODU2fDQ5LjU = with a DOI:10. 6070/H4DN432G.

PCR and qRT-PCR identification of known and novel miRNAs Total RNA (identical sample to that of the Solexa sequencing sample) was first digested with DNase I (Invitrogen), and $2 \mu \mathrm{g}$ of total RNA was reverse transcribed to poly (A) tail-added cDNA using the One Step PrimeScript miRNA cDNA Synthesis Kit (TaKaRa, Dalian) according to the manufacturer's instructions. Briefly, a 60-nt adaptor containing a poly (A) structure was added to the 3' sequence of miRNAs, which were then reverse transcribed to an 80-bp cDNA sequence [46]. The cDNA was diluted 5-fold with $\mathrm{ddH}_{2} \mathrm{O}$, and PCR was performed on a Bio-Rad system (BIO-RAD,USA )in a final $20 \mu \mathrm{L}$ volume reaction containing $2 \mu \mathrm{l}$ PCR cDNA, $10 \mu \mathrm{L}$ of $2 \times$ PCR Mix (Toyobo, Osaka, Japan) and $1 \mathrm{mM}$ of each primer. The real-time PCR thermal profile was as follows: 5 min at $95^{\circ} \mathrm{C}, 40$ cycles of $30 \mathrm{~s}$ at $94^{\circ} \mathrm{C}, 30 \mathrm{~s}$ at the corresponding annealing temperature $(\mathrm{Tm})$ and $72^{\circ} \mathrm{C}$ for $30 \mathrm{~s}$, followed by $72^{\circ} \mathrm{C}$ at $10 \mathrm{~min}$. PCR products were examined on an agarose gel to confirm that a single PCR product was generated, and 5S ribosomal RNA was used as an internal control for the PCR. The miRNA forward primer was designed with Primer 5.0 (Table 1), and the reverse primer for miRNAs was the Uni-miR qPCR Primer offered by the kit One Step PrimeScript miRNA cDNA Synthesis Kit (TaKaRa, Dalian).

\section{miRNAs target prediction and plasmid construction}

Two predicted novel miRNAs, named miR-PC-86 and miR-PC-263, were selected to predict their target genes in pig genome using the RNAhybrid software (http:// bibiserv.techfak.uni-bielefeld.de/rnahybrid/) with its own algorithm. The 3'-UTR sequences of porcine transcripts in whole genome were obtained from ensemble gene 66 (sscorfa 9, www.ensembl.org/Sus_scrofa/). The 3'-UTR of IGF-1R contains the highly conserved binding sites for the two miRNAs, and the sequence (104 bp) is as follows: TCCTGGATCCCGATCCCGTGCAAACAGTACCGTGCG CACGCGGGCGGGCGGGGGGAGAGTTTTAACAATCT ATTCACAAGCCTCCTGTACCTCAGTGGATCTTC. Further, the 3'-UTR sequence was inserted into pmirGLO Vector (Promega) with $\mathrm{XhoI}$ and $\mathrm{XbaI}$ double digestion to construct recombinant Dual-Luciferase reporter vector, named as pGLO-IGF-1R-3'UTR (Figure 1A). Meanwhile, a plasmid containing mutant IGF-1R 3'-UTR, named as pGLO-IGF-1R-3'UTR-delete (Figure 1A), was generated by deleting the core sequence of the two miRNA binding sites
Table 1 PCR primers for miRNAs

\begin{tabular}{|c|c|c|}
\hline miRNAs name & Primer sequence & $\begin{array}{l}\text { Renaturation } \\
\text { temperature }\end{array}$ \\
\hline ssc-let-7e & TGAGGTAGGAGGTTGTATAGTT & $59.5^{\circ} \mathrm{C}$ \\
\hline ssc-miR-21 & GCTAGCTTATCAGACTGATGTTG & $59.5^{\circ} \mathrm{C}$ \\
\hline ssc-miR-206 & TGGAATGTAAGGAAGTGTGTG & $59.5^{\circ} \mathrm{C}$ \\
\hline ssc- let-7i & GCCGCTGAGGTAGTAGTITGTGCT & $59.5^{\circ} \mathrm{C}$ \\
\hline ssc-miR-140 & GACAGTGGTTITACCCTATGGTA & $59.5^{\circ} \mathrm{C}$ \\
\hline ssc-miR-92b-5p & TTATAGGGACGGGACGCGGTG & $59.5^{\circ} \mathrm{C}$ \\
\hline ssc-miR-22b-3p & AAGCTGCCAGTTGAAGAACTG & $59.5^{\circ} \mathrm{C}$ \\
\hline ssc-miR-28-5p & GAAGGAGCTCACACTCTATTGA & $59.5^{\circ} \mathrm{C}$ \\
\hline ssc-miR-205 & TCCTTCATTCCACCGGAGTCT & $59.5^{\circ} \mathrm{C}$ \\
\hline ssc-miR-451 & AAACCGTTACCATTACTGAGTT & $59.5^{\circ} \mathrm{C}$ \\
\hline ssc-miR-125b & TCCCTGAGACCCTAACTTGTG & $59.5^{\circ} \mathrm{C}$ \\
\hline ssc-miR-9 & GCGGTCTITGGTTATCTAGCTGT & $59.5^{\circ} \mathrm{C}$ \\
\hline ssc-let-7c & TGAGGTAGTAGGTTGTATGGT & $59.5^{\circ} \mathrm{C}$ \\
\hline P-m0281-5p(PS-16) & TCTCCCAACCCTTGTACCA & $58^{\circ} \mathrm{C}$ \\
\hline P-m0124-3p(PC-280) & TGTTCCGAGATTGGGCTG & $58^{\circ} \mathrm{C}$ \\
\hline$P-m 0227-5 p(P C-291)$ & TTCCTGAGTCGGACTGGG & $58^{\circ} \mathrm{C}$ \\
\hline P-m0355-5p(PC-82) & CCCAGGATCAGAGGATGG & $58^{\circ} \mathrm{C}$ \\
\hline$P-m 0338-3 p(P C-241)$ & TCTGTGAACTAGAAACCTCTGG & $58^{\circ} \mathrm{C}$ \\
\hline P-m0105-3p(PC-72) & CATTTGATTCAGTTGGACACT & $58^{\circ} \mathrm{C}$ \\
\hline P-m0113-3p(PC-130) & CTATGGATCTAGGAGGACGC & $58^{\circ} \mathrm{C}$ \\
\hline P-m0129-5p(PC-129) & CTATGGATCTAAGAGGACACCC & $58^{\circ} \mathrm{C}$ \\
\hline$P-m 0058-5 p(P C-276)$ & TGTGTGTGATCGTTAATGTGC & $58^{\circ} \mathrm{C}$ \\
\hline$P-m 0279-5 p(P C-192)$ & GTCCTTGGTGAGTCGGATG & $58^{\circ} \mathrm{C}$ \\
\hline$P-m 0103-3 p(P C-70)$ & CATTGCTITGATCGTCTGG & $58^{\circ} \mathrm{C}$ \\
\hline P-m0265-3p(PC-139) & CTGGAAGGATTTGGGTAGG & $58^{\circ} \mathrm{C}$ \\
\hline$P-m 0210-5 p(P C-277)$ & TGTGTGTTCTGTCGGATGAG & $58^{\circ} \mathrm{C}$ \\
\hline P-m0186-5p(PC-73) & CATTITAAGGATCGTGTGGG & $58^{\circ} \mathrm{C}$ \\
\hline$P-m 0070-3 p(P C-63)$ & CAGTAGGGATGAGAGGACACT & $58^{\circ} \mathrm{C}$ \\
\hline
\end{tabular}

through DNA synthesis (Sangon Biotech (Shanghai) Co., Ltd.), the sequence is as follows: TCCTGGATCCCGATCC CGTGCAAACAGTACCGTGCGCACGCGGGCGGGCGG GGGGAGAGTTTTAACAATCTATTCACAAGCCTCCTG TACCC.

\section{Leuciferase reporter assay}

IPEC-J2 cells were maintained in DMEM/F12 (1:1) (GIBCO) and supplemented with $10 \%$ fetal bovine serum (FBS, GIBCO), $5 \mathrm{ng} / \mathrm{ml} \mathrm{EGF} \mathrm{(peprotech,} \mathrm{USA)} \mathrm{and} 5 \mathrm{ug} /$ $\mathrm{ml}$ insulin (Sigma, USA). Lipofectamine 2000 (Invitrogen) was used for transfection. Cells $(10,000)$ were plated in a 96-well plate. After $24 \mathrm{~h}$ cultivation, cells were transfected with a mixture including $500 \mathrm{ng}$ pGLO-IGF1R-3'UTR or pGLO-IGF-1R-3'UTR-delete construct and 30pM of miR-PC-86 or miR-PC-263 mimics (GenePharma, Shanghai, China). For control, 500 ng of pmirGLO- 


\section{A}

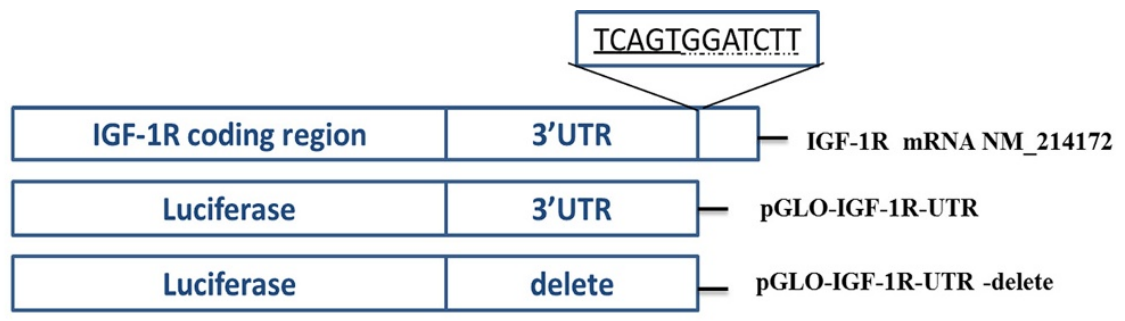

B

miR-PC-263 TGGGATCTGAGGACAGAAGGCGGA

miR-PC-86 CCCATTGAGAGCGAAGGTGGCA

IGF-1R mRNA(4133-4236) CTATTCACAAGCCTCCTGTACCTCAGTGGATCTTC

IGF-1R-delete CTATTCACAAGCCTCCTGTACCTCAGTGGATCTIC
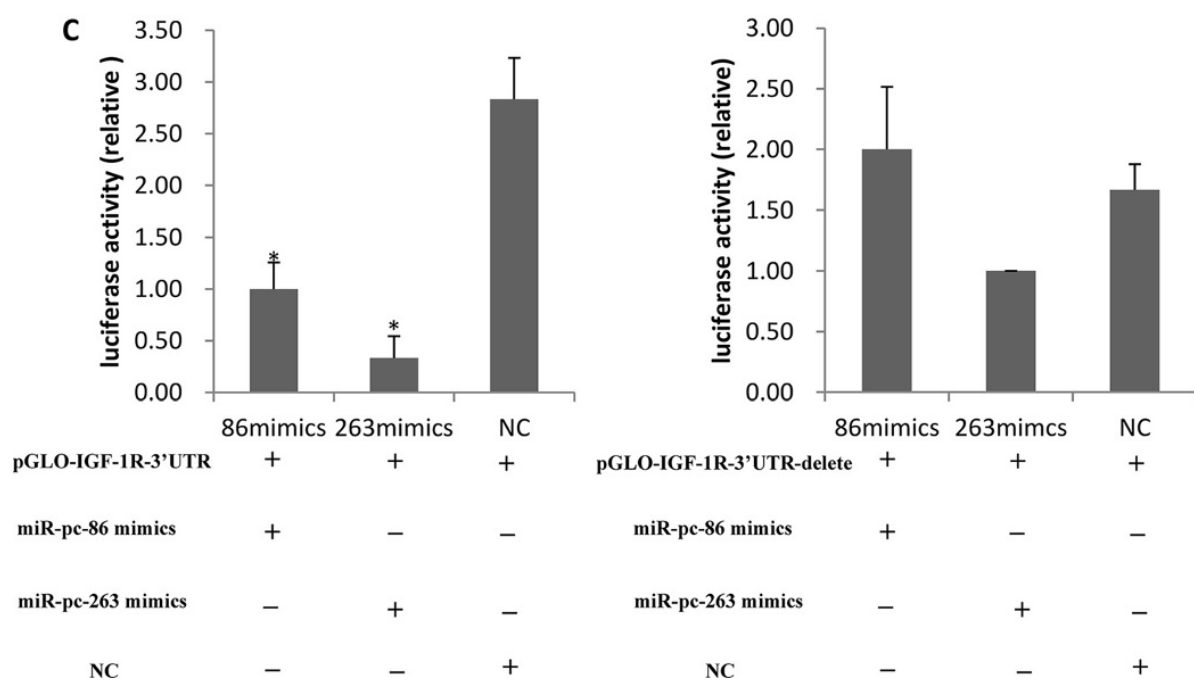

Figure 1 MiR-PC-86 and MiR-PC-263 directly regulate IGF-1R expression via 3' UTR sites. (A) Schematic of IGF-1R mRNA and the luciferase reporter plasmids containing the miR-PC-86 and miR-PC-263 binding sites of IGF-1R mRNA. The 3' UTR sites were inserted downstream of the luciferase reporter, as indicated. TCAGTGG was the predicted target site of miR-PC-86, GGATCTT was the predicted target site of miR-PC-263. (B) miR-PC-86 and miR-PC-263 sequences and predicted binding site between miR-PC-86 and miR-PC-263 and IGF-1R mRNA. IGF-1R mRNA has one putative binding site for miR-PC-86/ miR-PC-263 on the $3^{\prime}$ UTR. Twelve nucleotides TCAGTGGATCTT of IGF-1R $3^{\prime}$ UTR (underlined) were delete in order to disrupt the binding with miR-PC-86 and miR-PC-263 seed regions. (C) IPEC-J2 cells were transfected with each of the constructed plasmids, together with miR-PC-86/ miR-PC-263and Renilla luciferase reporter plasmid $\left({ }^{*} P<0.05, n=6\right)$.

scramble including a scrambled sequence of the miRNA target sequence was used. Cells were collected $48 \mathrm{~h}$ after transfection, and luciferase activity was measured using a Dual-GLO luciferase reporter assay system (Promega). Statistical differences between treatment and control groups were determined using Student's t-test, at $P<0.05$.

\section{Bioinformatics analysis}

Chromosomal localization and cluster analysis of miRNAs Pre-miRNAs of all miRNAs (known miRNAs and novel miRNAs) were mapped to the porcine genome (sscrofa9, www.ensembl.org/Sus_scrofa/) according to their positions on the chromosomes. Pre-miRNA positions less than $10 \mathrm{~kb}$ apart were considered to belong to the same miRNA cluster.

\section{Target prediction and Gene Ontology (GO) and Kyoto} Encyclopedia of Genes and Genomes (KEGG) pathway analyses

Porcine miRNA targets were obtained at the genome level. In brief, miRNA targets were predicted using the RNAhybrid software algorithm (http://bibiserv.techfak. uni-bielefeld.de/rnahybrid/) in 3'-UTR sequences of transcripts from the whole pig genome obtained from Ensembl Gene 66 database (sscrofa9, www.ensembl.org/ Sus_scrofa/). Strict criteria (perfect match of 2-8 nt in 

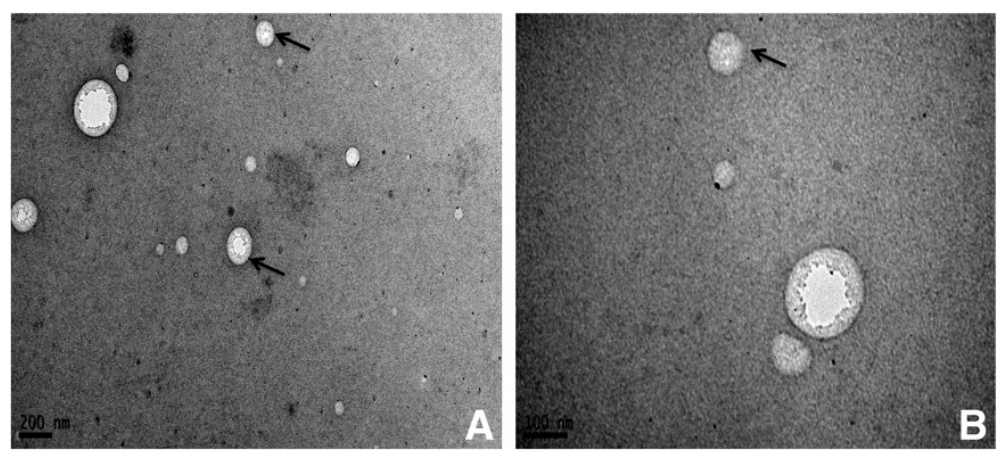

Figure 2 Exosomes detected by TEM. The exosomes appeared as round or oval microvesicles (A, B), with a diameter of 50-150 nm and heavier density at the center than on the margin.

the seed region; no more than $-25 \mathrm{kcal} / \mathrm{mol}$ low free energy of miRNAs-mRNA binding) were applied to the target prediction procedure. GO and KEGG pathway analyses were performed using DAVID bioinformatics resources (http://david.abcc.ncifcrf.gov/).

\section{Results}

\section{Identification of exosomes}

Exosomes were obtained from porcine milk by ultracentrifugation. After negative staining, approximately round-shaped porcine milk exosomes with diameters of $\sim 50-100 \mathrm{~nm}$ were observed by TEM, showing a greater density at the center than at the boundary (Figure 2A, B).

\section{Porcine milk exosomes contain RNA}

To further ascertain whether the porcine milk exosomes collected by ultracentrifugation contained RNA, we extracted the samples using Trizol reagent and then examined the recovered product by electrophoresis on a $2 \%$ agarose gel. To exclude the possibility of DNA contamination, total RNA was incubated at $37^{\circ} \mathrm{C}$ for $30 \mathrm{~min}$ with DNase I or RNase. The extracted RNA could not be digested by DNase I, while it could be degraded by RNase (Figure 3A). These results demonstrated that the porcine milk exosomes contained RNA. More interestingly, total RNA of porcine milk exosomes were enriched with 5S rRNA (Figure 3B), consistent with previous studies $[27,28,47]$.

\section{Solexa sequencing and analysis \\ Solexa sequencing}

The sRNAs were enriched from porcine exosomes to construct a library for Solexa sequencing. We obtained 9,033,167 raw reads and 6,013,724 high qualities reads after removal of low quality and contaminant reads. Among the high quality reads, there were 4,964,542 clean reads (82.55\%), representing 1,691,655 unique sRNAs. The majority of the sRNAs in porcine milk exosomes were $18-25 \mathrm{nt}$ in length (74.89\%, Figure 4), with 2,458,894 reads (49.53\%) representing 872,096 unique sRNAs (51.55\%), including miRNAs and other sRNAs, such as rRNA, tRNA, snRNA, snoRNA, scRNA, small recognition particle RNA (srpRNA), repetitive sequence elements and unannotated sequences,
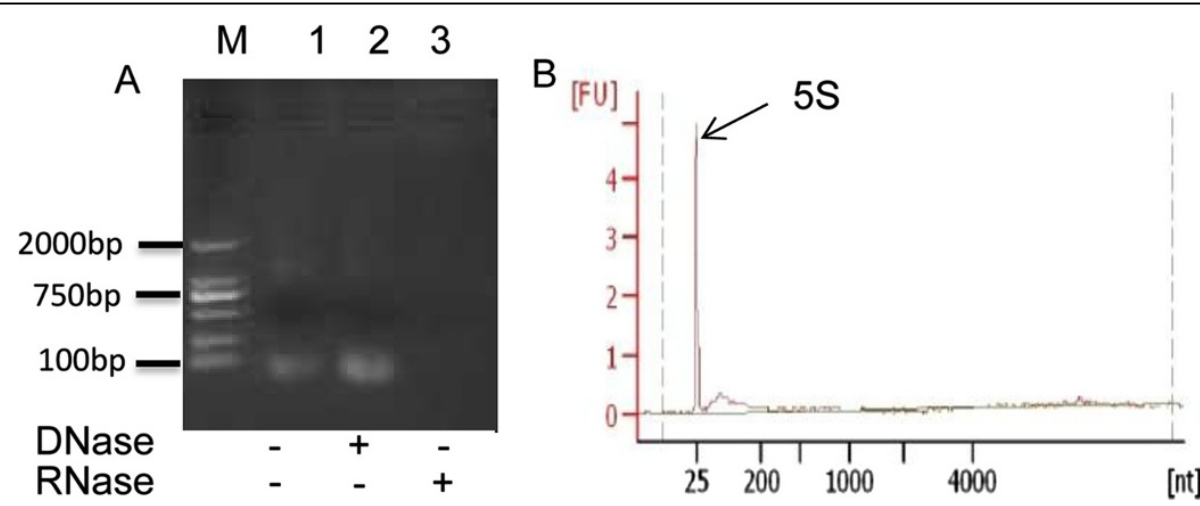

Figure 3 Milk-derived exosomes containing RNA. (A) Total RNA was extracted from porcine exosomes. M, 1, 2 and 3 represent the marker (DL 2000), RNA without any treatment, RNA treated with DNase I and RNA treated with RNase, respectively. (B) RNA sample analyzed by the Agilent Bioanalyzer 2100. 


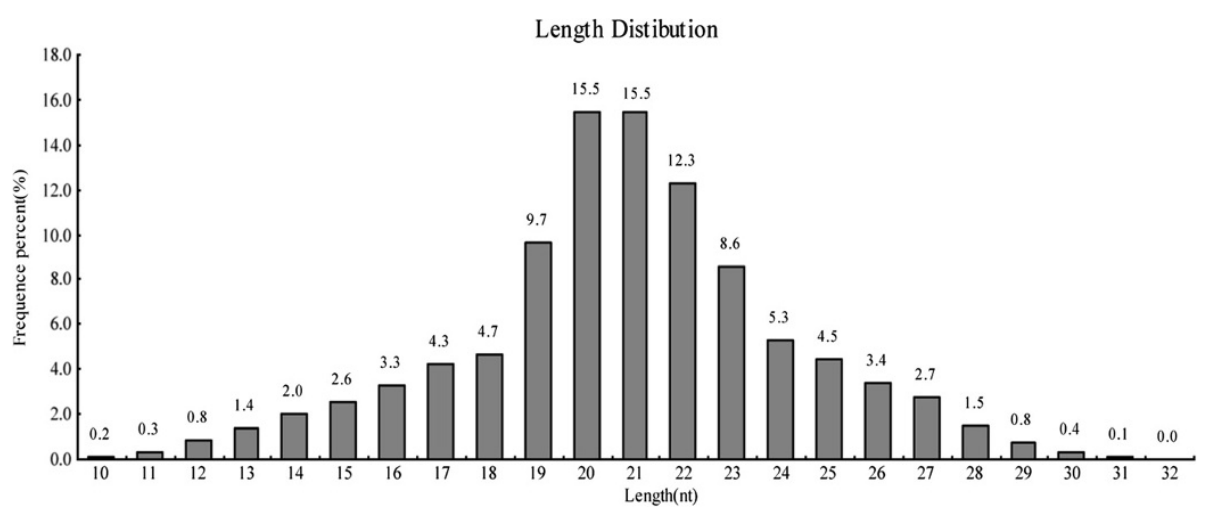

Figure 4 Length distribution of miRNAs reads from Solexa sequencing. A total of 4,964,542 clean reads were obtained, ranging from 10 to $32 \mathrm{nt}$, most of which were 18-25 nt in length (accounting for $74.89 \%$ ).

which could be mapped to the pig genome. BLAST searching with the miRbase 20.0, identified a total of 230,216 reads, representing 1,555 unique known miRNAs. Due to RNA bias editing, 5' modifications and 3' modifications, many pre-miRNAs produce multiple mature miRNA isoforms, namely isomiRNAs, as described in many studies [48-50]. In the subsequent analysis, all isomiRNAs generated from the same precursor were considered one type of miRNA. Consequently, these 1,555 unique miRNAs corresponded to 176 known mature miRNAs (205 pre-miRNAs, all the detail were listed in Additional file 1: Table S1). In addition, we identified 315 novel mature miRNAs (generated from 366 pre-miRNAs, detail in Additional file 2: Table S2). Among the 315 novel miRNAs, 18 have not been deposited as porcine miRNAs in miRbase 20.0, but had very high similarity with miRNA sequences of other species. These 18 miRNAs are labeled "PS" (Table 2), while 298 miRNAs that have not been deposited in miRbase 20.0 for any organism are labeled as "PC" and presented in Additional file 2: Table S2.

There were 73 miRNAs with more than 100 counts and 264 miRNAs with less than 10 counts. The top 10, top 20, top 50 and top 100 miRNAs accounted for

Table 2 Porcine novel miRNAs conserved in other species (miRBase release 20.0)

\begin{tabular}{|c|c|c|c|c|c|c|}
\hline Unique ID & miRNAs name & Count & Sequence & Size & Conservation & Match \\
\hline PS-1 & miR-290-5p & 14 & ACTCAAACTGTGGGGGCACTTT & 22 & $\mathrm{mmu}(\#)$ & 1nt sub(\#) \\
\hline PS-2 & miR-378c & 33 & ACTGGACTTGGAGTCAGAAGT & 21 & hsa & 4 nt delete \\
\hline PS-3 & miR-20b-3p & 4 & ACTGTAGTGTGGGCACTTCCAGT & 23 & hsa & $1 \mathrm{nt}$ add, 1 nt sub \\
\hline PS-4 & miR-219-3p & 11 & AGAATTGTGGCTGGACATCT & 20 & bta & 1nt delete \\
\hline PS-6 & miR-138-5p & 42 & AGCTGGTGTTGTGAATCAGGCCG & 23 & $\mathrm{mmu}$ & perfect \\
\hline PS-7 & miR-31-5p & 5 & AGGCAAGATGCTGGCATAGCT & 21 & has & perfect \\
\hline PS-9 & let-7f-1-3p & 2 & СTATACAATCTATTGCCTTCC & 21 & rno & perfect \\
\hline PS-11 & miR-874-3p & 25 & CTGCCCTGGCCCGAGGGACCGA & 22 & $\mathrm{mmu}$ & perfect \\
\hline PS-12 & miR-551a & 225 & GCGACCCACTCTTGGTTTCC & 20 & hsa & 1nt delete \\
\hline PS-13 & miR-138-3p & 1 & GCTACTTCACAACACCAGGGT & 21 & hsa & 1nt sub, 1 delete \\
\hline PS-14 & miR-182-3p & 1 & GGTGGTTCTAGACTTGCCAACT & 22 & $\mathrm{mmu}$ & $1 \mathrm{nt}$ insert \\
\hline PS-15 & miR-5003-3p & 58 & TATTTAATAGGTTGTTGGGA & 20 & hsa & 2 nt sub, 2 nt delete \\
\hline PS-16 & miR-150-5p & 164 & TCTCCCAACCCTTGTACCAGT & 21 & $\mathrm{mmu}$ & 1nt delete \\
\hline PS-17 & miR-2411-3p & 7 & TGAACTGTCATACTCCCACATC & 22 & bta & 3nt delete, 1 nt sub \\
\hline PS-18 & let-7f-5p & 20 & TGAGGTAGTAGATTGTATAGTTG & 23 & hsa & $1 \mathrm{nt}$ insert \\
\hline PS-19 & miR-31-3p & 3 & TGCTATGCCAACATATTGCCA & 21 & has & 1nt delete \\
\hline PS-20 & miR-182 & 46 & TTTGGCAATGGTAGAACTCACA & 22 & dre & perfect \\
\hline PS-21 & miR-96-5p & 65 & TTTGGCACTAGCACATTTTGCT & 23 & hsa & perfect \\
\hline
\end{tabular}

\#: mmu, Mus musculus; hsa, Homo sapiens; bta, Bos taurus; dre, Danio rerio; rno, Rattus norvegicus;

"sub", "delete", "add" represents nucleotide substitution, deletion, addition (at 5-end of miRNAs), respectively perfect stands for perfect match with reference miRNAs. 

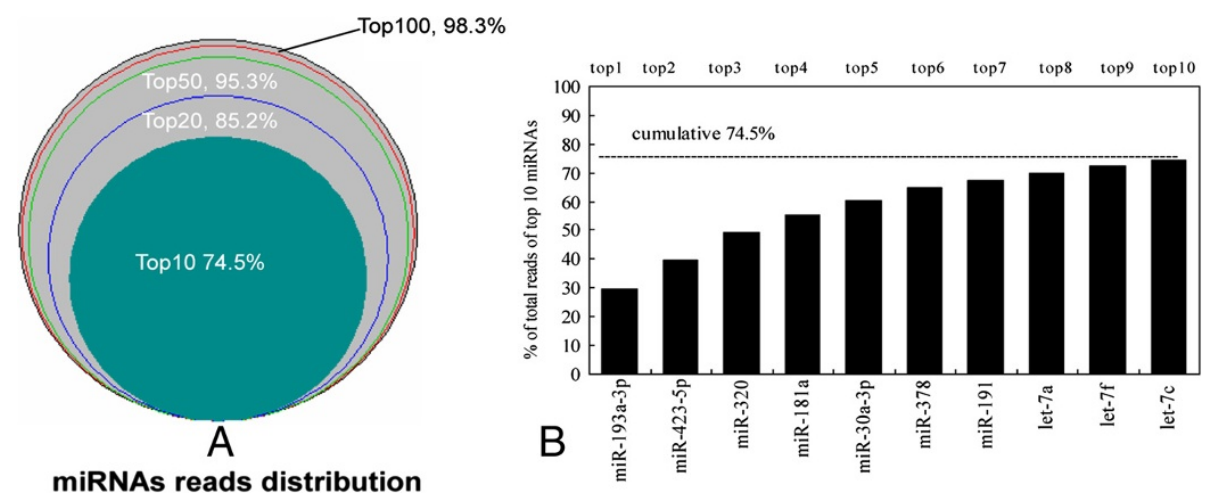

Figure 5 Distribution of miRNA reads and top 10 miRNAs. (A) The distribution of miRNA reads showed that the top 10, top 20, top 50 and top 100 miRNAs accounted for 74.5\%, 85.2\% and $95.3 \%$ and $98.3 \%$ of total reads. (B) Cumulative proportions of top 10 miRNAs. MiR-193-3p ranked first, accounting for $29.6 \%$ of total reads.

$74.5 \%, 85.2 \%, 95.3 \%$ and $98.3 \%$ of the reads, respectively (Figure 5A). The top 10 miRNAs were ssc-miR-193a-3p, ssc-miR-423-5p, ssc-miR-320, ssc-miR-181a, ssc-miR-30a3p, ssc-miR-378, ssc-miR-191, ssc-let-7a, ssc-let-7f and ssclet-7c. With 67,154 counts (29.6\%, average count: 460.6) (Figure 5B), ssc-miR-193a-3p ranked first among all miRNAs reads.

\section{Identification of miRNAs by PCR and sequencing}

To verify the deep sequencing results, we selected randomly 13 known miRNAs and 15 predicted novel miRNAs for PCR amplification (Figure 6A, B). Subsequently, the 15 newly predicted miRNAs were cloned and sequenced. The results showed that 8 sequences

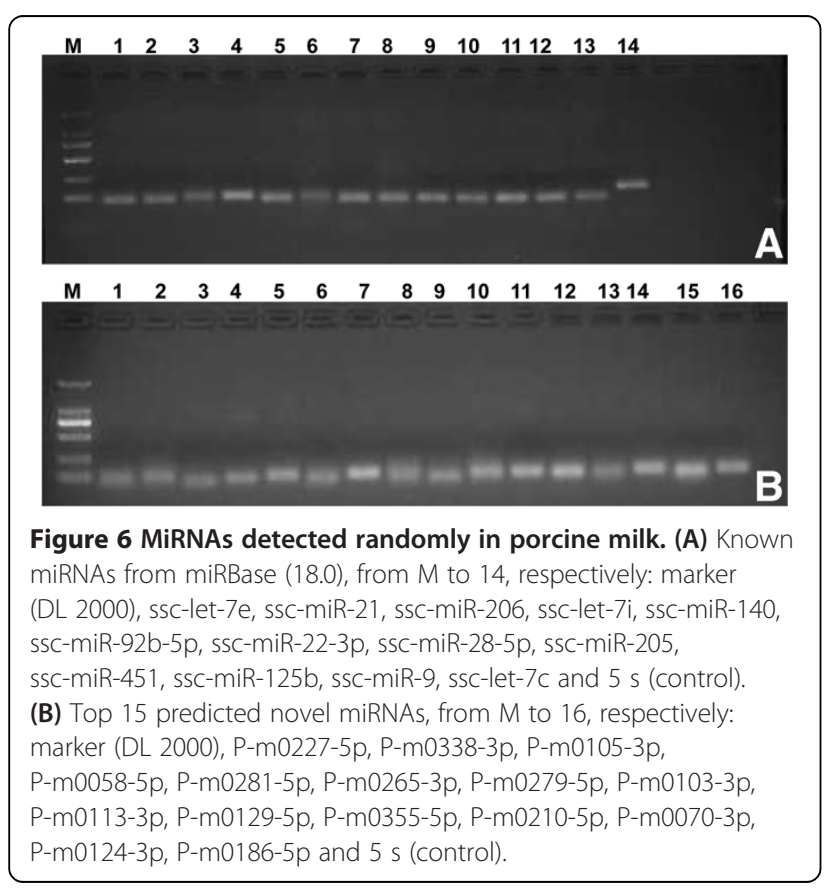

were fully matched, while 7 sequences had one or two mismatched nucleotides (Table 3). However their seed sequences remained unchanged. Simultaneously, the abundance of some novel miRNAs predicted by Solexa sequencing was confirmed by quantitative real-time PCR. The abundance of most miRNAs observed by qPCR of the sample pool and by sequencing were generally consistent (Figure 7).

Target verification of miR-PC-86 and miR-PC-263 against 3'UTR of IGF-1R using luciferase report assay

To investigate whether the predicted miR-PC-86 and miR-PC-263 (Figure 1) were functional novel miRNAs, target genes were predicted, and miR-PC-86/ miR-PC263 were found to directly target IGF-1R 3'UTR sequence. The full-length 3'UTR of IGF-1R mRNA was inserted downstream of the luciferase gene in the pmirGLO Dual-Luciferase miRNA Target Expression Vector reporter plasmid, and the seed sequence was also delete to disrupt miR-PC-86/ miR-PC-263 binding (Figure 1B). The wild-type (pGLO-IGF-1R-3'UTR) or delete (pGLOIGF-1R-3'UTR-delete) plasmid was co-transfected with the miR-PC-86 and miR-PC-263 mimics into IPEC-J2 cells. Forty-eight hours after transfection, the luciferase activity of the miR-PC-86 and miR-PC-263 group were significantly lower than that of the NC group $(\mathrm{P}<0.05)$ respectively, and the reduction was rescued in the delete group (Figure 1C). Thus, IGF-1R was initially confirmed as the target of miR-PC-86 and miR-PC-263.

\section{Genomic localization of pre-miRNAs}

To further establish the presence of miRNA precursors in the genome, all mature miRNAs (176 known and 315 novels) were mapped to the $S$. scrofa genome (Figure 8). As a result, 176 known mature miRNAs were mapped to 205 pre-miRNAs, and 315 novel miRNAs were mapped to 366 pre-miRNAs on the chromosomes. Our analysis 
Table 3 miRNAs matched to sequecing

\begin{tabular}{|c|c|}
\hline Predict new miRNA & Matched sequence \\
\hline \multirow[t]{3}{*}{ P-m0281-5p } & TСTCCCAACССTTGTACCACT \\
\hline & |||||||||||||||||||| \\
\hline & TCT CCCAACCCTTGTACCAGT \\
\hline \multirow[t]{3}{*}{ P-m0124-3p } & TGTTCCGAGATTGGGCTGCT \\
\hline & |||||||||||||||||| \\
\hline & TGTTCCGAGATTGGGCTGGC \\
\hline \multirow[t]{3}{*}{ P-m0227-5p } & TTCCTGAGTCGGACTGGGCT \\
\hline & $|1|||||||||||||||||$ \\
\hline & TTCCTGAGTCGGACTGGGCT \\
\hline \multirow[t]{3}{*}{ P-m0355-5p } & CCCAGGATCAGAGGATGGCTA \\
\hline & 111111111111111111 \\
\hline & CCCAGGATCAGAGGATGGACA \\
\hline \multirow[t]{3}{*}{ P-m0338-3p } & TCT GTGAACTAGAAA CCTCTGG \\
\hline & $11|1| 1|1| 1|1| 1|1| 1|1| 1 \mid$ \\
\hline & TCTGTGAACTAGAAACCTCTGG \\
\hline \multirow[t]{3}{*}{ P-m0105-3p } & CATTTGATTCAGTTGGACACT \\
\hline & $|1| 1|1| 1|1| 1|1| 1|1| 1 \mid$ \\
\hline & CATTTGATTCAGTTGGACACT \\
\hline \multirow[t]{3}{*}{ P-m0113-3p } & CTATGGATCTAGGAGGACGCA \\
\hline & $|1||||||||||||||||| \mid$ \\
\hline & CTATGGATCTAGGAGGACGCC \\
\hline
\end{tabular}

P-m0129-5p

P-m0058-5p
CTATGGATCTAAGAGGACACCC

|||||||||||||||||||||। CTATGGATCTAAGAGGACACCC

TGTGTGTGATCGTTAATGTGC

|||||||||||||||||||| $\mid$

TGTGTGTGATCGTTAATGTGC
Table 3 miRNAs matched to sequecing (Continued)

\begin{tabular}{|c|c|}
\hline \multirow[t]{3}{*}{ P-m0279-5p } & GTCCTTGGTGAGTCGGATGTC \\
\hline & $|1|||||||||||||||||||$ \\
\hline & GTCCTTGGTGAGTCGGATGTC \\
\hline \multirow[t]{3}{*}{ P-m0103-3p } & САTTGCTTTGATCGTCTGGC \\
\hline & |||||||||||||||||||| \\
\hline & СATTGCTTTGATCGTCTGGC \\
\hline \multirow[t]{3}{*}{ P-m0265-3p } & CTGGAAGGATTTGGGTAGGGA \\
\hline & $|1| 1|||1| 1|1| 1|1| 1$ \\
\hline & CTGGAAGGATTTGGGTAGGTC \\
\hline \multirow[t]{3}{*}{ P-m0210-5p } & TGTGTGTTCTGTCGGATGAGA \\
\hline & |||||||||||||||||||| \\
\hline & TGTGTGTTCTGTCGGATGAGC \\
\hline \multirow[t]{3}{*}{ P-m0186-5p } & САTTTTAAGGATCGTGTGGGT \\
\hline & $|1||||||||||||||||| \mid$ \\
\hline & САTTTTAAGGATCGTGTGGGG \\
\hline \multirow[t]{3}{*}{ P-m0070-3p } & CAGTAGGGATGAGAGGACACT \\
\hline & 11111111111111111111 \\
\hline & CAGTAGGGATGAGAGGACACT \\
\hline
\end{tabular}

revealed that the genomic density distribution of porcine milk pre-miRNAs (number of pre-miRNAs per Mb of each chromosome) was heterogeneous (Figure 8), ranging from 0.45 to 0.11 pre-miRNAs for $1 \mathrm{M}$ of genomic sequence. Chromosomes with the highest and lowest densities of pre-miRNAs were chromosome 12 (29 premiRNAs per $64 \mathrm{Mbp}$ ) and chromosome 13 (25 premiRNAs per $219 \mathrm{Mbp}$ ), respectively. Interestingly, the medium-length X chromosome (144 Mbp, ranking 10th in length among the 19 chromosomes in pigs) was an exception by encoding an intermediate number (25 out of $366,6.8 \%$ ) of pre-miRNAs, corresponding to 0.17 premiRNAs for $1 \mathrm{M}$ of genome sequence, but yet contained the most clusters.

In addition, we observed many mature miRNAs having multiple miRNA precursors located in the same or different chromosomes. Of the novel predicted miRNAs, 


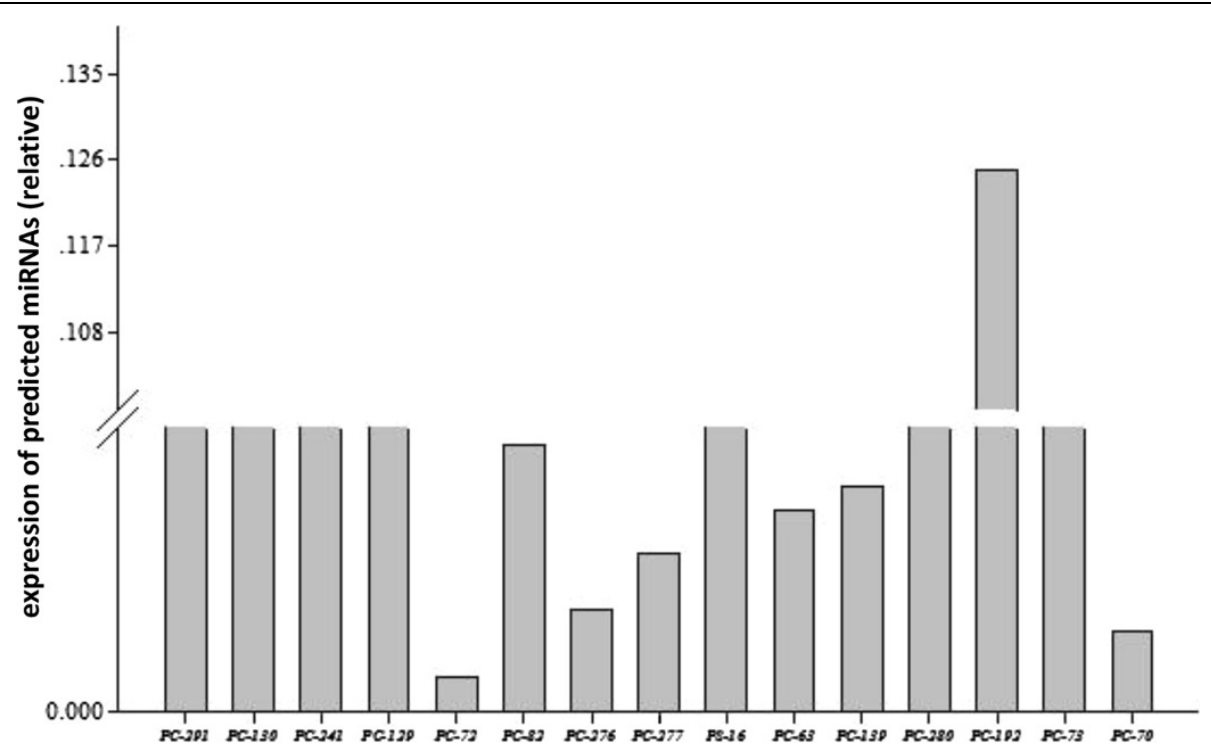

Figure 7 Expression of 15 predicted novel miRNAs in the sample pool detected by qRT-PCR. Trends in relative expression by qRT-PCR and counts from Solexa sequencing of miRNAs, except for PC-192, were consistent.

40 pre-miRNAs had two copies in the genome, 7 premiRNAs had 3 copies, 2 pre-miRNAs had 4 copies, 1 pre-miRNA had 8 copies and 249 pre-miRNAs were unique. With regard to known miRNAs, 4 pre-miRNAs had 3 copies, 22 pre-miRNAs had two copies and 149 pre-miRNAs had only one copy.

\section{Mature miRNAs}

It is well accepted that only one of two strands generated from a precursor is preferentially incorporated into RNA-induced silencing complexes (RISC), whereas the complementary strand (miR*) may be degraded. Closer examination of mature miRNAs generated from premiRNAs showed that precursor miRNAs could be divided into three groups (Table 4): pre-miRNAs only with the left-arm sequence (5p), pre-miRNAs only with the right-arm sequence or both. Most pre-miRNAs seemed to be single-arm miRNAs ( $5 p$ or $3 p$ ), while 50 premiRNAs possessed both $5 p$ and $3 p$ sequences (40 coupled mature miRNAs, all details were listed in Additional file 3: Table S3). Further analysis of the 40 coupled mature miRNAs indicated that most of the pre-miRNAs had no

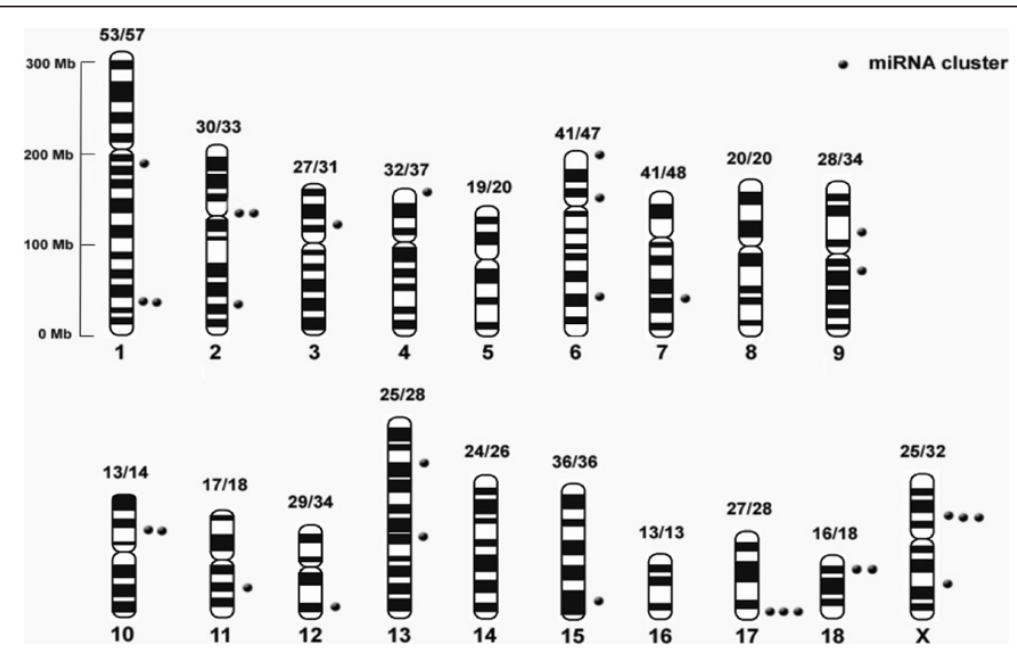

Figure 8 Distribution of $\mathbf{3 0}$ miRNA clusters. The number of base points near different bars indicates the number of clusters in the chromosome. The relative vertical dimension of the point on the bar represents the location of cluster. The label "number1 /number2" above every bar indicates the value of "pre-miRNAs/mature miRNA". 
Table 4 Pre-miRNAs and their corresponding mature miRNAs type

\begin{tabular}{llllll}
\hline & Pre-miRNAs & miRNA-5p & miRNA-3p & Both & $\begin{array}{l}\text { Mature } \\
\text { miRNAs }\end{array}$ \\
\hline known & 205 & 67 & 57 & $33(26) \#$ & 176 \\
novel & 366 & 150 & 139 & $17(13)$ & 315 \\
total & 571 & 217 & 196 & $50(39)$ & 491 \\
\hline
\end{tabular}

\#Number in bracket represents mature miRNAs couple number.

significant difference in abundance between the 5p-arm and $3 p-a r m$ sequences (Figure 9). Some miRNAs had different expression levels between the two strands. For example, ssc-miR-193a-3p had 67,154 counts, ranking first among all miRNAs, while ssc-miR-193a-5p had 2,538 counts. Conversely, miR-423-5p had 22,588 counts, while its complementary strand, miR-423-3p, had only 654 reads, and which was shared by miR-22, miR-30a, miR-339, miR-17, miR-24, miR-331, miR-27b and let-7d (detail in Additional file 3: Table S3).

As described in other studies [51], some small RNAs were generated from the loop or the region between the loop and stem (ssc-let-7e, ssc-miR-27a and ssc-miR-30a) (Figure 10A-C). In addition, we detected another interesting type of small RNAs known as miRNA-offset RNAs, or "moRNAs", which are derived from the ends of premiRNAs, predominantly from the 5 ' end, independent of the mature miRNA. A good example of moRNAs and small RNAs generated from the loop was pre-miR-30a (Figure 10C). At the 5' end of pre-miR-30, a 18 nt RNA sequence was found to be generated from the loop, downstream of ssc-miR-30a-5p (Figure 10C). The findings suggest that these RNAs may be only byproducts of Drosha and Dicer processing, or these small RNAs alternatively may take part in other important regulatory functions different from those of miRNAs.

\section{MiRNA clusters}

According to criteria for classification in miRbase, premiRNAs located on a chromosome with an interval of less than $10 \mathrm{~kb}$ are defined as belonging to an miRNA cluster. In our analysis, 30 (including 11 novel and 19 known) (Figure 8) clusters were detected (Table 5). Among all miRNAs clusters, there were several premiRNAs with intervening sequences of less than $1 \mathrm{~kb}$, including 10 known clusters (miR-99b/let-7e/125a, miR-24-2/27b/23b, miR-99a/let-7c, miR-29b/29a, miR-221/ 222, miR-98/let-7f, miR-181c/d, miR-363/92a/19b-2/106a, miR-363/92a/19b-2, miR-181b-1/181a-1 and miR-17/18a/ 19b-1/92a-1) and 4 novel miRNAs clusters (cluster 3, 9, 12, 22). We identified a typical polycistronic miRNA cluster, miR-363/92a/19b-2/20b, on chromosome X. Interestingly, the homologous cluster, miR-363/92a/19b-2/20b/106a on chromosome $\mathrm{X}$, was located $33.5 \mathrm{~kb}$ downstream of miR363/92a/19b-2/20b (Figure 11A, C), and a paraologous cluster miR-17/18a/19b-1/92a-1 was found on chromosome 11 (Figure 11B, C). The organization of miRNA precursors in the genome may account for variable levels of expression and regulation of mature miRNAs.

\section{MiRNA families}

It is widely believed that the members of a given miRNA family regulate very similar sets of target genes. Apart from miRNA clusters, miRNA families were also recognized in the miRNAs of exosomes. Based on seed sequences, 35 miRNA families were identified ( 26 known and 9 novel miRNA families) to contain at least two members and the identification of novel miRNAs added
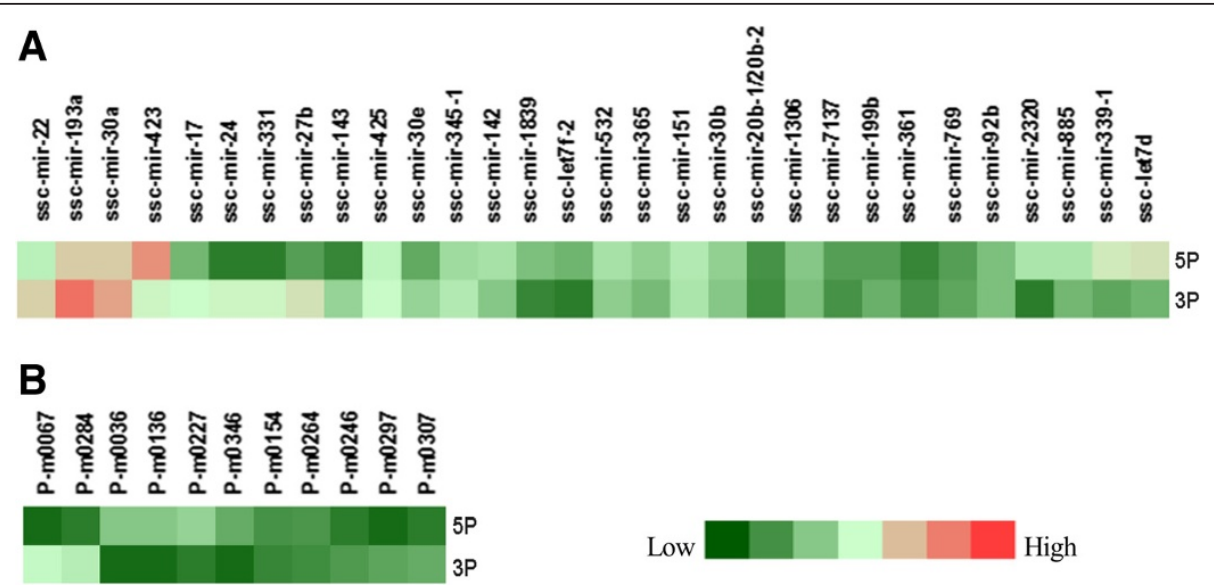

Figure $95 p$ and 3p arm expression of 46 pre-miRNAs. (A) 30 known pre-miRNAs. (B) 11 novel pre-miRNAs (representing 15 coupled $3 p$ and $5 p$ arm sequences). 


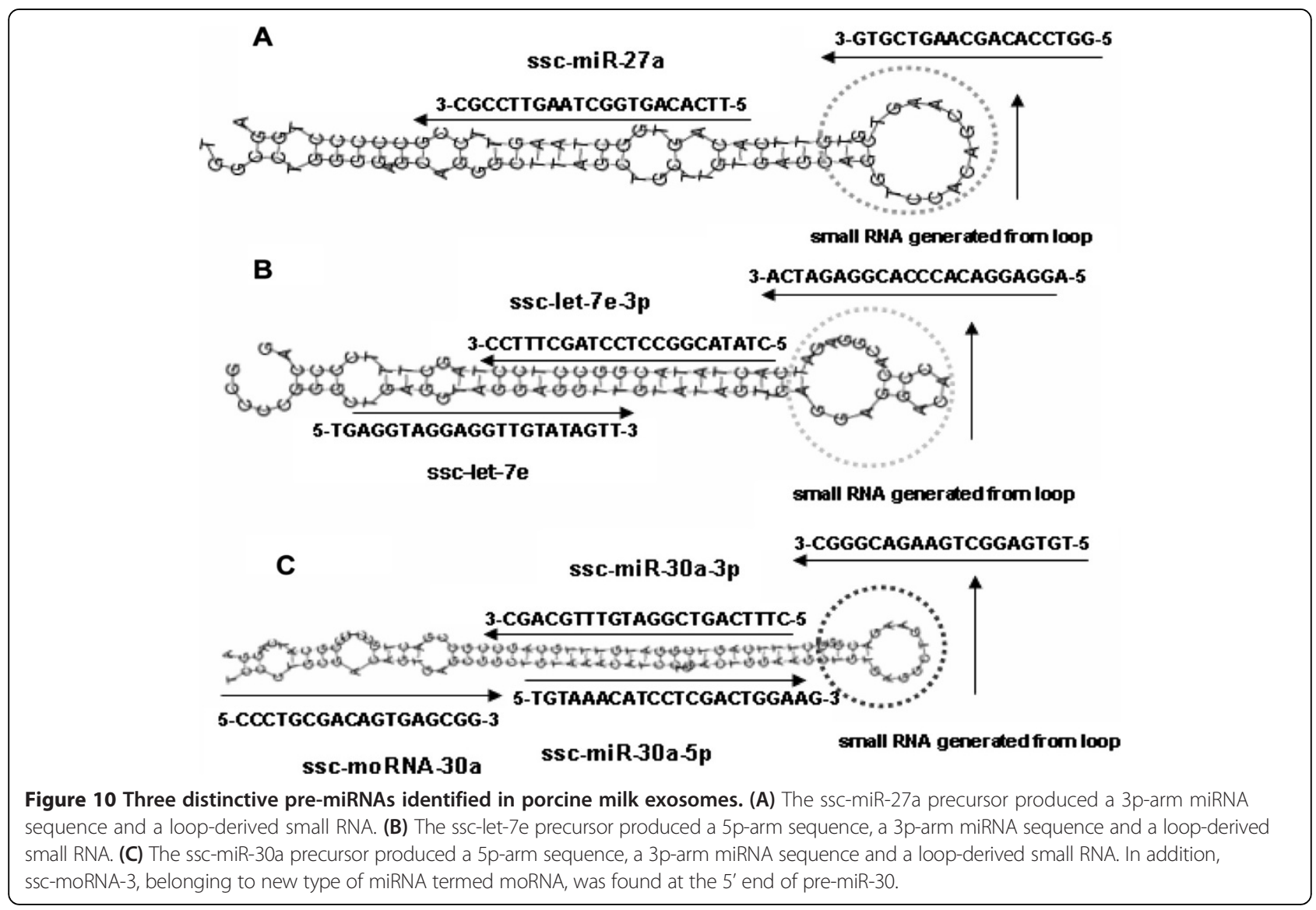

new members to 5 known families (Table 6). In our study, 8 miRNA families (let-7, mir-1, mir-17, mir-181, mir-148, mir-30, mir-92 and mir-99) were found with at least 3 members among all exosome miRNAs. The let-7 family had 9 members, miR-181 family had 4 members (miR-181a/b/c/d) and miR-30 family had 5 members (miR-30a/b/c/d/e). Most importantly, these miRNAs were highly expressed, and let-7 family members (let-7a/ $\mathrm{f} / \mathrm{c}$ ), miR-181a and miR-30a-3p were enriched among the top 10 miRNAs. However, members in the same family were highly differentially expressed. In the miR-181 family, miR-181a and miR-181b were dominant types with 13,345 reads and 3,333 reads, respectively. Similarly, miR-30a was the most abundant in the miR-30 family. The differential expression of members in the same family may be partly due to regulation of their precursors [52]. On the other hand, combined with the cluster analysis, we also observed that some miRNAs shared not only the same cluster but also the same families. These miRNAs included $181 \mathrm{a} / \mathrm{b}$, let-7f/miR-98, 181c/d, let-7a/f-5p/d-5p, 30b/d, 30c/e and miR-221/222. More interestingly, family members of the same cluster seemed to share expression patterns (Figure 12A-E). As mentioned above, miR-17-5p, miR-363, miR-106a,
miR-18a, miR-19b, miR-92a, miR-20b and miR-92b formed a complex cluster and family network, and they also showed different expression patterns. MiR-92a, miR-19b and miR-363 were found to be highly expressed, while miR-17-5p, miR-18a, miR-20b and miR-106a were lowly expressed. The difference in abundance of the homologous or paralogous clusters may be attributed to the copy number of miRNA precursor itself or to the post-transcriptional regulation of the process of generating a mature miRNA from the precursor miRNA.

In addition, many miRNA families showed low expression (count number $<100$ ) in milk exosomes, such as the miR-1, miR-130, miR-17, miR-10, miR-29, miR-374, mir-9, miR-15 and miR-491 families (Figure 12F), which are routinely expressed in specific tissues [53-56]. Interestingly, all 9 novel miRNAs families showed extremely low expression levels (Figure 12G, count number $<50$ ), indicating that these miRNAs may only be expressed in certain physiology processes and may be the reason for why these miRNAs have not been detected until now. MiR-148a was reported to be an important biomarker for milk exosome miRNAs $[28,57]$. In this study, three members of this family (miR-148a, miR-148b and 
Table 5 miRNAs cluster

\begin{tabular}{|c|c|c|c|}
\hline $\begin{array}{l}\text { Cluster } \\
\text { No. }\end{array}$ & Cluster name & members & chromosome \\
\hline cluster 1 & new & p-m0165, p-m0166 & 1 \\
\hline cluster 2 & mir-181a-2/181b-2 & $\begin{array}{l}\text { ssc-mir-181a-2, } \\
\text { ssc-mir-181b-2 }\end{array}$ & 1 \\
\hline cluster 3 & new & ssc-miR-199b, P-m0179 & 1 \\
\hline cluster 4 & miR-24-1/27a/23a & $\begin{array}{l}\text { ssc-mir-24-1, } \\
\text { ssc-miR-27a, } \\
\text { ssc-mir-23a }\end{array}$ & 2 \\
\hline cluster 5 & miR-181c/d & $\begin{array}{l}\text { ssc-miR-181c, } \\
\text { ssc-mir-181d }\end{array}$ & 2 \\
\hline cluster 6 & miR-143/145 & $\begin{array}{l}\text { ssc-mir-143, } \\
\text { ssc-miR-145 }\end{array}$ & 2 \\
\hline cluster 7 & $\begin{array}{l}\text { let-7a/let-7f-2/let- } \\
7 d\end{array}$ & $\begin{array}{l}\text { ssc-let-7a-2, P-m0204, } \\
\text { ssc-let-7f-2, ssc-let-7d }\end{array}$ & 3 \\
\hline cluster 8 & miR-30d/30b & $\begin{array}{l}\text { ssc-mir-30d, ssc-mir- } \\
30 b\end{array}$ & 4 \\
\hline cluster 9 & new & P-m0263, P-m0264 & 6 \\
\hline cluster 10 & $\begin{array}{l}\text { mir-99b/let-7e/ } \\
125 a\end{array}$ & $\begin{array}{l}\text { ssc-mir-99b, ssc-let-7e, } \\
\text { ssc-mir-125a }\end{array}$ & 6 \\
\hline cluster 11 & $\begin{array}{l}\text { mir-30c-1/ mir- } \\
30 e\end{array}$ & $\begin{array}{l}\text { ssc-mir-30c-1,ssc-mir- } \\
30 e\end{array}$ & 6 \\
\hline Cluster 12 & new & P-m0302,P-m0318 & 7 \\
\hline cluster 13 & let-7a-1/miR-100 & ssc-let-7a-1, ssc-mir-100 & 9 \\
\hline cluster 14 & new & $\begin{array}{l}\text { P-m0346, P-m0347, } \\
\text { P-m0348,P-m0349 }\end{array}$ & 9 \\
\hline cluster 15 & ${ }_{1}^{\operatorname{miR}-181 b-1 / 181 a-}$ & $\begin{array}{l}\text { ssc-mir-181b-1, } \\
\text { ssc-mir-181a-1 }\end{array}$ & 10 \\
\hline cluster 16 & miR-24-2/27b/23b & $\begin{array}{l}\text { ssc-mir-24-2, } \\
\text { ssc-mir-27b, } \\
\text { ssc-mir-23b }\end{array}$ & 10 \\
\hline cluster 17 & miR-17-92a-1 & $\begin{array}{l}\text { ssc-mir-17, } \\
\text { ssc-mir-18a, } \\
\text { ssc-mir-19b-1, } \\
\text { ssc-mir-92a-1 }\end{array}$ & 11 \\
\hline cluster 18 & new & $\begin{array}{l}\text { P-m0024, P-m0025, } \\
\text { P-m0026 }\end{array}$ & 12 \\
\hline cluster 19 & miR-425/191 & $\begin{array}{l}\text { ssc-mir-425, } \\
\text { ssc-mir-191 }\end{array}$ & 13 \\
\hline cluster 20 & miR-99a/let-7c & $\begin{array}{l}\text { ssc-mir-99a, } \\
\text { ssc-let-7c }\end{array}$ & 13 \\
\hline cluster 21 & new & $\begin{array}{l}\text { P-m0099, } \\
\text { P-m0083 }\end{array}$ & 15 \\
\hline cluster 22 & new & $\begin{array}{l}\text { P-m0124, } \\
\text { P-m0113 }\end{array}$ & 17 \\
\hline cluster 23 & new & $\begin{array}{l}\text { P-m0125, P-m0126, } \\
\text { P-m0127, P-m0128, } \\
\text { P-m0114 }\end{array}$ & 17 \\
\hline cluster 24 & new & P-m0130, P-m0131 & 17 \\
\hline cluster 25 & miR-29b-1/29a & $\begin{array}{l}\text { ssc-mir-29b-1, ssc-mir- } \\
29 a\end{array}$ & 18 \\
\hline cluster 26 & new & $\begin{array}{l}\text { P-m0136, P-m0137, } \\
\text { ssc-mir-183 }\end{array}$ & 18 \\
\hline cluster 27 & miR-221/222 & ssc-mir-221, ssc-mir-222 & $x$ \\
\hline
\end{tabular}

Table 5 miRNAs cluster (Continued)

\begin{tabular}{llll}
\hline cluster 28 & miR-98/let-7f-1 & ssc-mir-98, ssc-let-7f-1 & $X$ \\
cluster 29 & miR-363 20b & ssc-mir-363-1, & $X$ \\
& & ssc-mir-92a-2, & \\
& ssc-mir-19b-2, & \\
& P-m0370, \\
& sc-mir-20b- \\
& & 1/ssc-mir-20b-2 & \\
Cluster 30 miR-363 20b & ssc-mir-363-1, & $X$ \\
& & ssc-mir-92a-2, & \\
& & ssc-mir-19b-2, \\
& & P-m0371, \\
& & ssc-mir-20b-1/ssc- \\
& mir-20b-2, \\
& ssc-miR-106a \\
\hline
\end{tabular}

miR-152, Figure 12H) showed modest expression levels, suggesting that miR-148 may be a stably expressed miRNA in exosomes of most mammals including pigs.

\section{GO and KEGG pathway analyses}

To better understand the role of miRNAs in pig milk exosomes, potential targets of miRNAs at the pig genome level were explored by using our previous method [58]. We selected the top 10 miRNAs for target prediction using RNAhybrid, which found 2,333 potential transcripts. GO analysis showed that those targets were enriched in many processes (Table 7), including antigen processing and presentation, MHC class II protein complex and transcription. Pathways analysis revealed these targets were enriched in 7 KEGG pathways (Table 8), which are essential for piglet metabolism (glycerophospholipid metabolism and citrate cycle), immunity (cell adhesion molecules, asthma and intestinal immune network for IgA production, antigen processing and presentation) and development (Notch signaling pathway). The results suggest that these milk miRNAs likely take part in regulation of important protective functions in piglets, including the intestinal immune network for IgA production and antigen processing and presentation.

\section{Targets of miRNAs in IgA immune network}

As shown by GO and KEGG analysis, many of the identified miRNAs were predicted to participate in immunity, similar to findings of other studies [28]. To further understand those miRNAs, the top 20 predicted miRNAs were selected for in-depth analysis of the IgA immune network. The results showed that 14 of the top 20 miRNAs are likely involved in the IgA network and may target about 20 immune-related genes (APRIL, CCL25, CD40, CD80, CD86, ICOS, IL10, IL-5, ITGB7, LOC100621559, LTBR, MADCAM1, SLA, SLA-DMA, SLA-DMB, SLA-DOB, SLA-DQA1, SLA-DRA, SLA-DRB1 and TGFB3) (Figure 13). These results suggest that porcine milk miRNAs take part in regulation of the IgA 


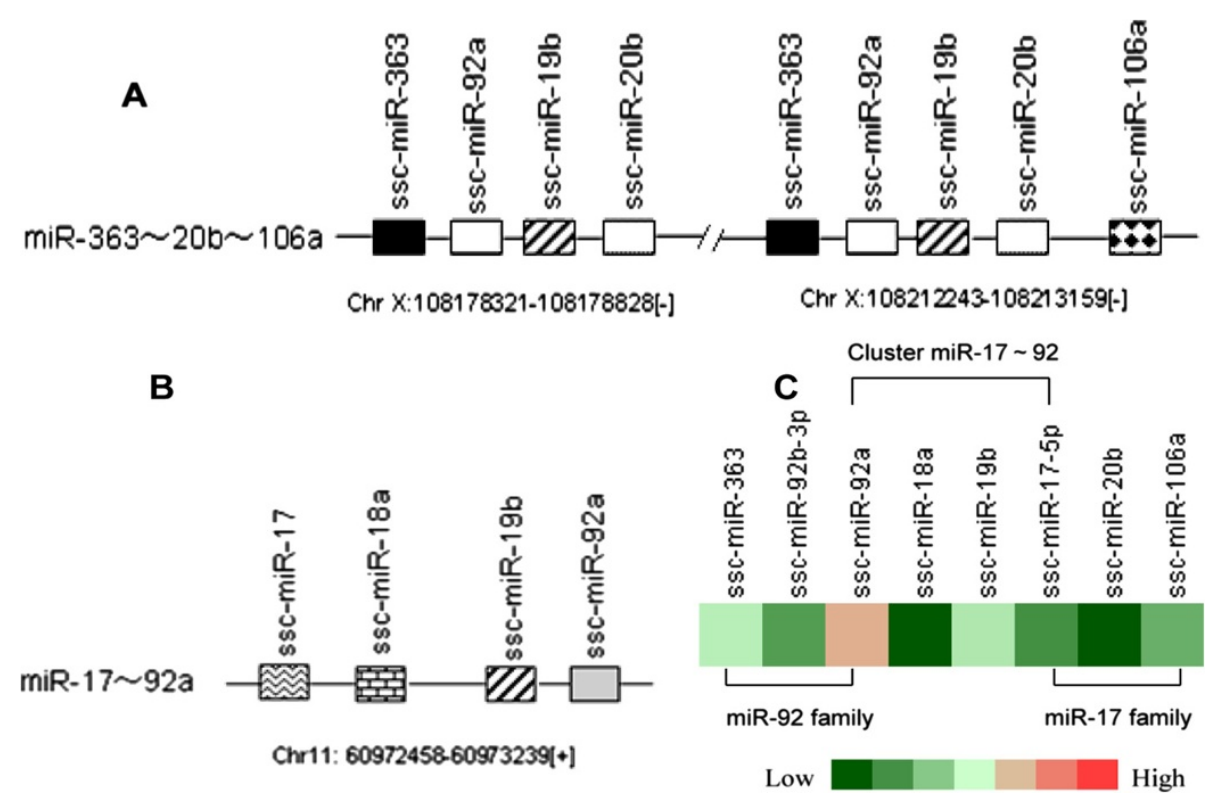

Figure 11 MiR-363 20b 106a homologous or paralogous cluster and expression level. (A) The miR-363/92a/19b/20b cluster and its homologous cluster miR-363/92a/19b/20b/106a on chromosome X were separated by a 33.5 kb DNA fragment. (B) The miR-17/18a/19/92a cluster was located on chromosome 11. In the genome, miR-92a/19b showed three copies; miR-363 and miR-20b had two copies; while miR-17, miR-18a and miR-106a had one copy. (C) Expression of mature miRNAs produced from the miR-363 20b 106a cluster and miR-17 92 cluster.

network and immunity of piglets. In addition, several miRNAs shared the same target gene. Interestingly, all of the let-7 family members (let-7a, let-7c and let-7f) could target CCL25. Those miRNAs are proposed to play a key role in IgA production in the piglet digestive tract and deserve further exploration, as mucosal immunity is critically important for the protection of newborn piglets.

\section{Discussion}

In the present study, a comprehensive miRNA expression profile of porcine breast milk exosomes was explored via a deep sequencing approach. We found in total 176 known miRNAs (miRBase 20.0) and 366 premiRNAs producing 315 mature miRNAs. Luciferase reporter assay was used to explore the targets of two predicted novel miRNAs in this study. Results indicated both of them down-regulated the luciferase expression by targeting 3'UTR of IGF-1R. All these pre-miRNAs were distributed in 30 clusters (11 novel and 19 known clusters), and the mature miRNAs could be assigned to 35 families (26 known and 9 unknown families). GO and KEGG pathway analyses show that those miRNAs may participate in many different immune-related processes. An analysis of the top 20 miRNAs showed that 14 of them may be involved in many regulatory aspects of the IgA immune network.
A recent study of exosome miRNAs in Yorkshire sow milk discovered 180 pre-miRNAs, including 140 known porcine pre-miRNAs and 40 novel pre-miRNAs, which encode 237 mature miRNAs (234 unique miRNAs) [29] In the current study, we discovered 205 known porcine pre-miRNAs (176 mature miRNAs) and 366 novel premiRNAs (315 mature miRNAs), approximately 254 more mature miRNAs than were revealed in the former report [29]. Therefore, our results substantially supplement the known pig miRNAs, particularly milk exosome miRNAs. Interestingly, most of the novel miRNAs were low in abundance (312 miRNAs with less than 100 reads and only 3 miRNAs with $>100$ reads), which is possibly the reason for why these miRNAs were not detected in a previous study by Gu et al. [29]. Further comparison revealed that miR-191 and let-7a, which potentially play a vital role in immunity, were found in both that study and in the top 10 miRNAs of our study. Other miRNAs identified previously (miR-30a-5p, miR-25-3p, miR-182$5 p$, miR-200c-3p and miR-375-3p) were not detected in our study. Furthermore, miR-148a, a potential biomarker for quality control in bovine milk [57] and human milk [28], which was found to be highly expressed throughout the lactation period of Yorkshire sows [29], was only detected at a moderate level in Landrace pigs in our study. MiR-148a has been reported to be a tumor metastasis suppressor in gastric cancer [59], and ectopic expression of miR-148a was shown to induce apoptosis and silence 
Table 6 miRNAs family

\begin{tabular}{|c|c|c|c|}
\hline & Family & Seed & $\mathrm{N}$ \\
\hline Family 1 & let-7 & GAGGTAG & 9 \\
\hline Family 2 & mir-1 & GGAATGT & 3 \\
\hline Family 3 & mir-10 & ACCCTGT & 2 \\
\hline Family 4 & mir-103 & GCAGCAT & 2 \\
\hline Family 5 & mir-125 & CCCTGAG & 2 \\
\hline Family 6 & mir-130 & AGTGCAA & 2 \\
\hline Family 7 & mir-148 & CAGTGCA & 3 \\
\hline Family 8 & mir-17 & AAAGTGC & 3 \\
\hline Family 9 & mir-181 & ACATTCA & 4 \\
\hline Family 10 & mir-186 & AAAGAAT & 2 \\
\hline Family 11 & mir-193 & ACTGGCC & 2 \\
\hline Family 12 & mir-221 & GCTACAT & 2 \\
\hline Family 13 & mir-23 & TCACATT & 2 \\
\hline Family 14 & mir-27 & TCACAGT & 2 \\
\hline Family 15 & mir-29 & AGCACCA & 2 \\
\hline Family 16 & mir-30 & GTAAACA & 5 \\
\hline
\end{tabular}

Family 17 mir-30(\#) TTCAGT 2

Family 18 mir-339 CCCTGTC 2

Family 19 mir-34 GGCAGTG 2

Family 20 mir-363 ATTGCAC 3

Family 22 mir-378 CTGGACT 2

Family 23 mir-491 GTGGGGA 2

Family 24 mir-497 AGCAGCA 4

Family 25 mir-9 CTाTGGT 2

Family 26 mir-99 ACCCGTA 3
Members

ssc-let-7i, ssc-miR-98,

ssc-let-7a,ssc-let-7f,

ssc-let-7c, ssc-let-7 g,

ssc-let-7e, ssc-let7d-5p

ssc-miR-1, ssc-miR-206,

PC-117

ssc-miR-10b,

ssc-miR-10a

ssc-miR-107,

sSC-miR-103

sSc-miR-125a,

ssc-miR-125b

ssc-miR-130b,

ssc-miR-130a

ssc-miR-148b,

ssc-miR-152,

ssc-miR-148a

ssc-miR-106a,

ssc-miR-17-5p,

ssc-mir-20b-1/ssc-mir-20b-2

ssc-miR-181a,

ssc-miR-181b,

ssc-miR-181c,

ssc-miR-181d-5p

ssc-miR-186, PC-36

ssc-miR-193a-3p, PC-3

ssc-miR-222, ssc-miR-221

ssc-miR-23b, ssc-miR-23a

ssc-miR-27a,ssc-miR-27b

ssc-miR-29b, ssc-miR-29c

ssc-miR-30e-5p,

ssc-miR-30c,

ssc-miR-30d,

ssc-miR-30b-5p,

ssc-miR-30a-5p

ssc-miR-30a-3p,

ssc-miR-30e-3p

ssc-miR-339-5p,

ssc-miR-4334-3p

ssc-miR-34c,

ssc-miR-34a,

ssc-miR-363,

ssc-miR-92b-3p,

ssc-miR-92a

ssc-miR-374b-5p

ssc-miR-374a,

ssc-miR-378, PS-2

ssc-miR-491, PC-122

ssc-miR-497, ssc-miR-15b, ssc-miR-16, ssc-miR-15a

ssc-miR-9-2, ssc-miR-9-1,

ssc-miR-99a,

ssc-miR-99b,

ssc-miR-100
Table 6 miRNAs family (Continued)

\begin{tabular}{|c|c|c|c|c|}
\hline Family 27 & new-1 & CATGATT & 2 & $\begin{array}{l}\text { P-m0040-3p(PC-9), } \\
\text { P-m0240-5p(PC-232), }\end{array}$ \\
\hline Family 28 & new-2 & AGAGGGA & 2 & $\begin{array}{l}P-m 0048-3 p(P C-152), \\
P-m 0064-3 p(P C-217)\end{array}$ \\
\hline Family 29 & new-3 & ATTGAT & 2 & $\begin{array}{l}P-m 0084-5 p(P C-228), \\
P-m 0105-3 p(P C-72),\end{array}$ \\
\hline Family 30 & new-4 & GCTAGGA & 2 & $\begin{array}{l}\text { P-m0110-5p(PC-112), } \\
\text { P-m0139-5p(PC-111) }\end{array}$ \\
\hline Family 31 & new-5 & TATGGAT & 2 & $\begin{array}{l}P-m 0113-3 p(P C-130), \\
P-m 0129-5 p(P C-129)\end{array}$ \\
\hline Family 32 & new-6 & CCTGGAT & 2 & $\begin{array}{l}\text { P-m0142-5p(PC-164), } \\
\text { P-m0179-3p(PC-165) }\end{array}$ \\
\hline Family 33 & new-7 & CATATTT & 2 & $\begin{array}{l}\text { P-m0161-3p(PC-231), } \\
\text { P-m0244-3p(PC-162) }\end{array}$ \\
\hline Family 34 & new-8 & GTTGGA & 2 & $\begin{array}{l}\text { P-m0183-3p(PC-286), } \\
\text { P-m0325-5p(PC-128) }\end{array}$ \\
\hline Family 35 & new-9 & $\mathrm{C} T \mathrm{TGGG}$ & 2 & $\begin{array}{l}P-m 0229-5 p(P C-15) \\
P-m 0342-3 p(P C-105)\end{array}$ \\
\hline
\end{tabular}

The underline indicated this family contains novel miRNAs. \#: due to miRNAs classification by seed sequence, $3 p$ and $5 p$ of miR-30 represent different miRNAs families. PC is unique ID for porcine miRNAs candidate.

Bcl-2 in colorectal cancer cells [60]. By bioinformatics analysis, miR-148a was determined to be possibly related to immunity and gastrointestinal health, but the underlying regulatory mechanism remains unclear.

MiR-92a belongs to the miR-17 $\sim 92$ cluster with seven miRNAs (miR-17-5p, miR-17-3p, miR-18a, miR-19a, miR-19b, miR-20a and miR-92a) and was first described as an oncogenic miRNA cluster involved in B-cell lymphoma [61]. Recent studies indicated that the miRNA-17-92 (miR-17-92) cluster directly targets the TGFB pathway in cancer cell lines in the mouse embryo stage [62]. In addition, the miR-17-92 cluster also participates in normal development of the heart, lungs and immune system [63]. MiR-19 can promote leukemogenesis in Notch1-induced T-cell acute lymphoblastic leukemia (T-ALL) in vivo [64]. Overexpression of the mir-17-mir-18a-mir-19b-1 cluster was shown to accelerate Myc-induced tumor development in a mouse B-cell lymphoma model [61]. The combined results above imply that members of the cluster miR-363/ 92a/19b-2/20b/106a may be related to cell proliferation and development. In porcine milk, miR-363/92a/19b-2/20b (miR-363/92a/19b-2/20b/106a) and miR-17/18a/19b-1/921 were also detected. The miR-181 $(181 \mathrm{a} / \mathrm{b} / \mathrm{c} / \mathrm{d})$ family is related to the development of different cells. It was reported that miR-181c/d can inhibit cell cycle and proliferation and that miR-181c regulates TNF- $\alpha$ [65]. The miR-30(b/c/d/e) family regulates kidney development by targeting the transcription factor Xlim1/Lhx1 in Xenopus [66]. The wellknown let-7(a/b/d/f) family is involved in oncogene expression [67], and let-7/miR-98 family members are expressed late in mammalian embryonic development [68]. Thus, 


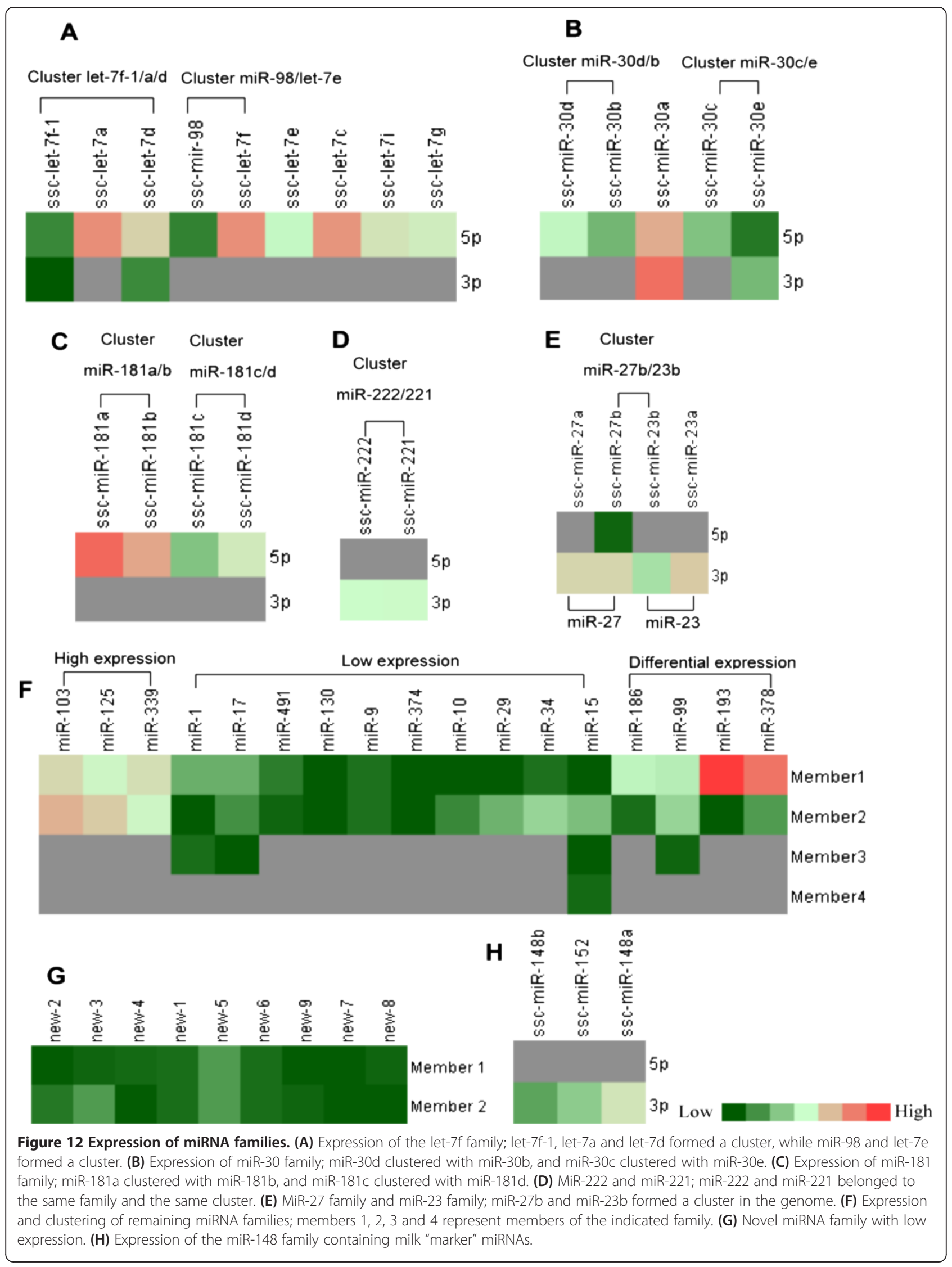


Table 7 Gene ontology analysis of potential targets of top10 miRNAs

\begin{tabular}{|c|c|c|c|}
\hline Category & Term & Count & P-Value \\
\hline Biological process & transcription & 15 & $6.70 \mathrm{E}-03$ \\
\hline Biological process & regulation of transcription & 21 & 1.00E-02 \\
\hline Biological process & $\begin{array}{l}\text { antigen processing and } \\
\text { presentation }\end{array}$ & 7 & $1.50 \mathrm{E}-02$ \\
\hline Biological process & $\begin{array}{l}\text { regulation of RNA } \\
\text { metabolic process }\end{array}$ & 17 & 1.70E-02 \\
\hline Biological process & $\begin{array}{l}\text { regulation of transcription, } \\
\text { DNA-dependent }\end{array}$ & 17 & 1.70E-02 \\
\hline Biological process & $\begin{array}{l}\text { antigen processing and } \\
\text { presentation of peptide } \\
\text { or polysaccharide antigen } \\
\text { via MHC class II }\end{array}$ & 4 & 2.20E-02 \\
\hline $\begin{array}{l}\text { Cellular } \\
\text { Component }\end{array}$ & $\begin{array}{l}\text { MHC class II protein } \\
\text { complex }\end{array}$ & 6 & 3.70E-04 \\
\hline $\begin{array}{l}\text { Cellular } \\
\text { Component }\end{array}$ & MHC protein complex & 7 & 5.00E-03 \\
\hline $\begin{array}{l}\text { Cellular } \\
\text { Component }\end{array}$ & large ribosomal subunit & 3 & 2.90E-02 \\
\hline $\begin{array}{l}\text { Molecular } \\
\text { Function }\end{array}$ & $\begin{array}{l}\text { transcription regulator } \\
\text { activity }\end{array}$ & 20 & 1.80E-03 \\
\hline $\begin{array}{l}\text { Molecular } \\
\text { Function }\end{array}$ & $\begin{array}{l}\text { sequence-specific } \\
\text { DNA binding }\end{array}$ & 13 & 2.60E-03 \\
\hline $\begin{array}{l}\text { Molecular } \\
\text { Function }\end{array}$ & $\begin{array}{l}\text { ligand-dependent nuclear } \\
\text { receptor activity }\end{array}$ & 7 & $5.80 \mathrm{E}-03$ \\
\hline $\begin{array}{l}\text { Molecular } \\
\text { Function }\end{array}$ & transcription factor activity & 15 & $1.20 \mathrm{E}-02$ \\
\hline $\begin{array}{l}\text { Molecular } \\
\text { Function }\end{array}$ & $\begin{array}{l}\text { steroid hormone } \\
\text { receptor activity }\end{array}$ & 6 & 2.10E-02 \\
\hline $\begin{array}{l}\text { Molecular } \\
\text { Function }\end{array}$ & DNA binding & 20 & 2.40E-02 \\
\hline $\begin{array}{l}\text { Molecular } \\
\text { Function }\end{array}$ & $\begin{array}{l}\text { phosphatase regulator } \\
\text { activity }\end{array}$ & 4 & 2.90E-02 \\
\hline $\begin{array}{l}\text { Molecular } \\
\text { Function }\end{array}$ & $\begin{array}{l}\text { protein phosphatase } \\
\text { regulator activity }\end{array}$ & 4 & 2.90E-02 \\
\hline
\end{tabular}

these miRNAs mentioned above may participate in development of the piglet digestive tract.

Notably, some miRNAs among the top 10 identified here have been reported to be related to immunity (miR-320, miR-181a, miR-30a-3p, let-7a, let-7f and let-7c) and development (miR-193a-3p, miR-378 and miR-191). MiR-193a-3p was demonstrated to regulate cell proliferation, cell cycle progression in vitro and in nude mice [69]. MiR-378 promotes osteoblast differentiation by targeting polypeptide $\mathrm{N}$-acetylgalactosaminyltransferase 7 (GalNAc-T7 or GalNT7) [70], and miR-191 regulates erythroid differentiation in mammals by up-regulating erythroidenriched genes Riok3 and Mxi1 [71]. Meanwhile, miR-320 is able to inhibit HL-60 cell proliferation by suppressing receptor 1 (TfR-1; CD71) [72], and miR-181a was believed to act as an intrinsic antigen sensitivity "rheostat"
Table 8 KEGG pathway analysis of potential targets of top10 miRNAs

\begin{tabular}{|c|c|c|c|}
\hline Term & Count & gene & p-value \\
\hline $\begin{array}{l}\text { ssc04514: Cell adhesion } \\
\text { molecules (CAMs) }\end{array}$ & 14 & $\begin{array}{l}\text { CADM3, CD4, CD40, } \\
\text { F11R, LOC100521555, } \\
\text { SELE, SELL, SELP, SLA, } \\
\text { SLA-DMA, SLA-DOA, } \\
\text { SLA-DOB, SLA-DRA, } \\
\text { SLA-DRB1 }\end{array}$ & $1.65 \mathrm{E}-03$ \\
\hline ssc05310: Asthma & 7 & $\begin{array}{l}\text { CD40, SLA, SLA-DMA, } \\
\text { SLA-DOA, SLA-DOB, } \\
\text { SLA-DRA, SLA-DRB1 }\end{array}$ & $5.55 \mathrm{E}-03$ \\
\hline $\begin{array}{l}\text { ssc04672: Intestinal immune } \\
\text { network for IgA production }\end{array}$ & 8 & $\begin{array}{l}\text { CD40, SLA, SLA-DMA, } \\
\text { SLA-DOA, SLA-DOB, } \\
\text { SLA-DRA, SLA-DRB1, } \\
\text { TGFB3 }\end{array}$ & $2.15 \mathrm{E}-02$ \\
\hline $\begin{array}{l}\text { ssc04330: Notch signaling } \\
\text { pathway }\end{array}$ & 5 & $\begin{array}{l}\text { DLL4, PTCRA, } \\
\text { LOC733643, } \\
\text { APH1A, NOTCH4 }\end{array}$ & $2.33 \mathrm{E}-02$ \\
\hline $\begin{array}{l}\text { ssc04612: Antigen processing } \\
\text { and presentation }\end{array}$ & 10 & $\begin{array}{l}\text { CD4, LOC100152370, } \\
\text { NFYB, PSME1, SLA, } \\
\text { SLA-DMA, SLA-DOA, } \\
\text { SLA-DOB, SLA-DRA, } \\
\text { SLA-DRB1 }\end{array}$ & $3.00 \mathrm{E}-02$ \\
\hline $\begin{array}{l}\text { ssc00564:Glycerophospholipid } \\
\text { metabolism }\end{array}$ & 6 & $\begin{array}{l}\text { AGPAT1, AGPAT4, } \\
\text { |AGPAT6, GNPAT, } \\
\text { LOC100152491, } \\
\text { PCYT1B }\end{array}$ & 4.25E-02 \\
\hline $\begin{array}{l}\text { ssc00020:Citrate cycle } \\
\text { (TCA cycle) }\end{array}$ & 5 & $\begin{array}{l}\text { ACO2,DLST, IDH2, } \\
\text { LOC100157889, } \\
\text { PCK1 }\end{array}$ & 4.57E-02 \\
\hline
\end{tabular}

during T cell development [73]. MiR-320, miR-181a, miR-30a-3p and let-7 were shown to be downregulated in colorectal cancer [74]. Of course, further experimental evidence is needed to verify that these miRNAs are indeed related to immunity of the piglet digestive tract.

IgA is a major immunoglobulin in milk [75]. Expression of the polymeric IgA receptor $(p I g R)$ in mammary epithelial cells contribute much to the development of the immune system at the early stage of lactation [76]. In the present study, some miRNAs were predicted to target genes (CD40, SLA, SLA-DMA, SLA-DOA, SLA$D O B, S L A-D R A, S L A-D R B 1$ and TGFB3) involved in processes of the intestinal immune network for IgA production in porcine milk. CD40 is a B-cell antigen activated during immune responses [77]. CD40 and CD40 ligand $(C D 40 L)$ expressed on activated $\mathrm{T}$ cells are essential to B cell proliferation [78] and secretion of IgG, IgA and IgE [79]. SLA Class I were found to be expressed in the epithelial and lamina propria cells of the intestine in adult pigs and to be involved in mother-newborn interactions [80]. A study in humans showed that TGF- $\beta$ acts as a specific switch for IgA present at early stages of development of $\mathrm{B}$ cells [81]. 


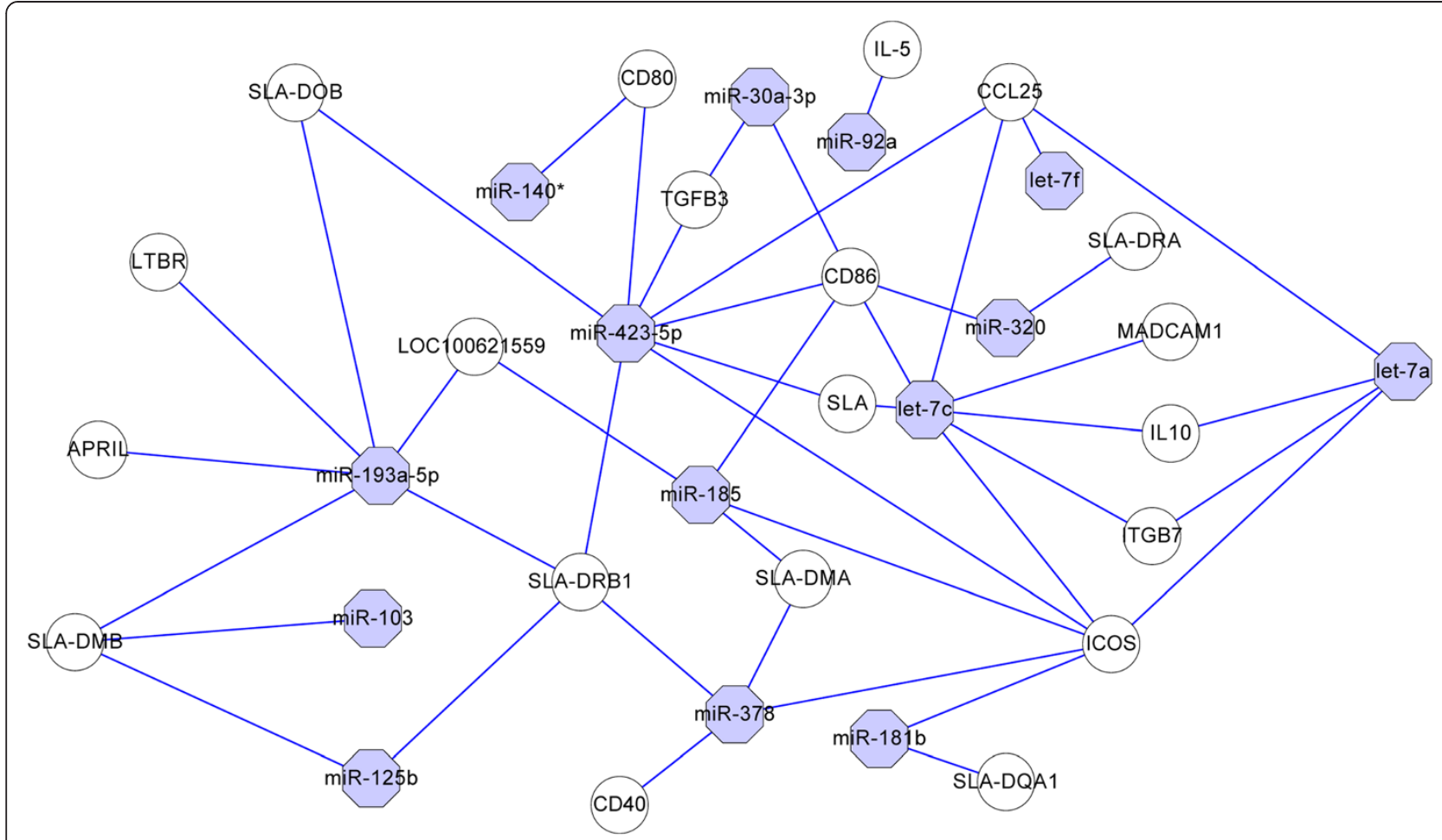

Figure 13 MiRNAs targeting the IgA immune network. The top 20 miRNAs were analyzed, and 14 of them were found to participate in the IgA immune network, involving 20 target genes. Different colors and shapes represent various relationships between miRNAs and genes.

In the present study, the top 20 miRNAs were used for IgA network analysis. APRIL was the predicted target of miR-193a-5p, which is essential to triggering $\mathrm{IgA}_{2}$ class switch in human $\mathrm{B}$ cells. Intestinal epithelial cells (IECs) release APRIL after sensing bacteria through Toll-like receptors, and mucosal vaccines activate IECs to induce more effective $\operatorname{IgA}_{2}$ responses [82]. The let7 family and miR-423-5p were predicted to target CCL25, a potent and selective chemoattractant for IgA antibody-secreting cells [83]. CCL25 is known to selectively modulate immune responses, specifically the localization of $\mathrm{T}$ lymphocytes to the small-intestinal mucosa [84]. CD80 and CD86, which are costimulators of $\mathrm{T}$ lymphocytes [85], were identified as possible targets of five miRNAs in our study. Let-7a, let-7c, miR-181b, miR-185, miR-378 and miR-423-5p were predicted to target the inducible costimulatory molecule (ICOS), which plays a key role in regulating $\mathrm{T}$-cell differentiation, T-cell proliferation, and secretion of lymphokines, providing effective help for antibody secretion by B cells [86]. We hypothesize that some miRNAs identified here in porcine milk regulate IgA production in the intestine of piglets, which may play an important role in mucosa immunity. However, their regulatory mechanisms warrant further study.

\section{Conclusions}

In conclusion, the present study revealed 176 known miRNAs and 366 (315 mature miRNAs) novel pre-miRNAs in porcine milk, most of which were predicted to be involved in regulation of digestive tract development and immunity of newborn piglets. These findings contribute to an increased understanding of the roles of miRNAs in porcine (S. scrofa) milk exosomes and to building the foundation for understanding their physiological functions and regulatory mechanisms.

\section{Availability of supporting data}

All the supporting data has been deposited in https:// mynotebook.labarchives.com/share/allinchen/MTkuNX wxMzMxMS8xNS0yL1RyZWVOb2RILzE1NzEyODU2f DQ5LjU = with a DOI:10.6070/H4DN432G.

\section{Additional files}

Additional file 1: Table S1. 176 known mature miRNAs.xls.

Additional file 2: Table S2. 315 novel miRNAs.xls.

Additional file 3: Table S3. Pre-miRNAs with $3 p$ and $5 p$ sequence.xls.

Competing interests

We declared this manuscript have no competing interests. 


\section{Authors' contributions}

TC, QX carried out the miRNAs Solexa Sequencing and data analysis, and participated in drafted the manuscript. XC, QQ carried out the PCR, QPCR. GS, SW participated in the sample collected. XZ, NW performed the Transmission electron microscopy. RY, QJ YZ conceived of the study, and participated in its design and coordination and helped to draft the manuscript. All authors read and approved the final manuscript.

\section{Acknowledgements}

This work was supported by grants from the Key Project of Guangdong Provincial Nature Science Foundation (S2013020012766), National Basic Research Program of China (973 Program, 2011CB944200, 2009CB941600 and 2013CB127304), Natural Science Foundation of China program (31272529) and the Natural Science Foundation of Guangdong Province (S2013010013215). We thank the breeding farm of the Livestock Research Institute (Guangzhou, China) for providing milk samples.

Received: 8 March 2013 Accepted: 31 January 2014

Published: 5 February 2014

\section{References}

1. Strobel S: Immunity induced after a feed of antigen during early life: oral tolerance v. sensitisation. Proc Nutr Soc 2001, 60(4):437-442.

2. Armogida SA, Yannaras NM, Melton AL, Srivastava MD: Identification and quantification of innate immune system mediators in human breast milk. Allergy Asthma Proc 2004, 25(5):297-304

3. Kramer MS, Chalmers B, Hodnett ED, Sevkovskaya Z, Dzikovich I, Shapiro S, Collet JP, Vanilovich I, Mezen I, Ducruet T: Promotion of breastfeeding intervention trial (PROBIT). JAMA 2001, 285(4):413-420

4. Høst A, Koletzko B, Dreborg S, Muraro A, Wahn U, Aggett P, Bresson J, Hernell O, Lafeber $\mathrm{H}$, Michaelsen $\mathrm{K}$ : Dietary products used in infants for treatment and prevention of food allergy. Arch Dis Child 1999, 81(1):80-84.

5. Van Niel G, Porto-Carreiro I, Simoes S, Raposo G: Exosomes: a common pathway for a specialized function. J Biochem 2006, 140(1):13-21.

6. Pan BT, Johnstone RM: Fate of the transferrin receptor during maturation of sheep reticulocytes in vitro: selective externalization of the receptor. Cell 1983, 33(3):967-978.

7. Théry C, Regnault A, Garin J, Wolfers J, Zitvogel L, Ricciardi-Castagnoli P, Raposo G, Amigorena S: Molecular characterization of dendritic cell-derived exosomes. J Cell Biol 1999, 147(3):599-610.

8. Raposo G, Nijman HW, Stoorvogel W, Liejendekker R, Harding CV, Melief C, Geuze HJ: B lymphocytes secrete antigen-presenting vesicles. J Exp Med 1996, 183(3):1161-1172.

9. Blanchard N, Lankar D, Faure F, Regnault A, Dumont C, Raposo G, Hivroz C: TCR activation of human T cells induces the production of exosomes bearing the TCR/CD3/乙 complex. J Immunol 2002, 168(7):3235-3241.

10. Raposo G, Tenza D, Mecheri S, Peronet R, Bonnerot C, Desaymard C. Accumulation of major histocompatibility complex class II molecules in mast cell secretory granules and their release upon degranulation. Mol Biol Cell 1997, 8(12):2631-2645.

11. Van Niel G, Raposo G, Candalh C, Boussac M, Hershberg R, Cerf-Bensussan N, Heyman M: Intestinal epithelial cells secrete exosome-like vesicles. Gastroenterology 2001, 121(2):337-349.

12. Mears R, Craven RA, Hanrahan S, Totty N, Upton C, Young SL, Patel P, Selby PJ, Banks RE: Proteomic analysis of melanoma-derived exosomes by two-dimensional polyacrylamide gel electrophoresis and mass spectrometry. Proteomics 2004, 4(12):4019-4031.

13. Gonzalez-Begne M, Lu B, Han X, Hagen FK, Hand AR, Melvin JE, Yates JR III: Proteomic analysis of human parotid gland exosomes by multidimensional protein identification technology (MudPIT). J Proteome Res 2009, 8(3):1304-1314.

14. Ogawa Y, Kanai-Azuma M, Akimoto Y, Kawakami H, Yanoshita R: Exosome-like vesicles with dipeptidyl peptidase IV in human saliva. Biol Pharm Bull 2008, 31(6):1059-1062.

15. García JM, García V, Peña C, Domínguez G, Silva J, Diaz R, Espinosa P, Citores MJ, Collado M, Bonilla F: Extracellular plasma RNA from colon cancer patients is confined in a vesicle-like structure and is mRNA-enriched. RNA 2008, 14(7):1424-1432.

16. Pisitkun T, Shen RF, Knepper MA: Identification and proteomic profiling of exosomes in human urine. Proc Natl Acad Sci USA 2004, 101(36):13368.
17. Keller S, Rupp C, Stoeck A, Runz S, Fogel M, Lugert S, Hager H, Abdel-Bakky M, Gutwein P, Altevogt P: CD24 is a marker of exosomes secreted into urine and amniotic fluid. Kidney Int 2007, 72(9):1095-1102.

18. Runz S, Keller S, Rupp C, Stoeck A, Issa Y, Koensgen D, Mustea A, Sehouli J, Kristiansen $G$, Altevogt P: Malignant ascites-derived exosomes of ovarian carcinoma patients contain CD24 and EpCAM. Gynecol Oncol 2007, 107(3):563-571.

19. Prado N, Marazuela EG, Segura E, Fernández-García H, Villalba M, Théry C, Rodríguez R, Batanero E: Exosomes from bronchoalveolar fluid of tolerized mice prevent allergic reaction. J Immunol 2008, 181(2):1519-1525.

20. Simpson RJ, Jensen SS, Lim JWE: Proteomic profiling of exosomes: current perspectives. Proteomics 2008, 8(19):4083-4099.

21. Deregibus MC, Cantaluppi V, Calogero R, lacono ML, Tetta C, Biancone L, Bruno S, Bussolati B, Camussi G: Endothelial progenitor cell-derived microvesicles activate an angiogenic program in endothelial cells by a horizontal transfer of mRNA. Blood 2007, 110(7):2440-2448.

22. Lakkaraju A, Rodriguez-Boulan E: Itinerant exosomes: emerging roles in cell and tissue polarity. Trends Cell Biol 2008, 18(5):199-209.

23. Schorey JS, Bhatnagar S: Exosome function: from tumor immunology to pathogen biology. Traffic 2008, 9(6):871-881

24. Valadi H, Ekström K, Bossios A, Sjöstrand M, Lee JJ, Lötvall JO: Exosomemediated transfer of mRNAs and microRNAs is a novel mechanism of genetic exchange between cells. Nat Cell Biol 2007, 9(6):654-659.

25. Nakatani H, Aoki N, Nakagawa Y, Jin-No S, Aoyama K, Oshima K, Ohira S, Sato C, Nadano D, Matsuda T: Weaning-induced expression of a milk-fat globule protein, MFG-E8, in mouse mammary glands, as demonstrated by the analyses of its $\mathrm{mRNA}$, protein and phosphatidylserine-binding activity. Biochem J 2006, 395(Pt 1):21.

26. Admyre C, Johansson SM, Qazi KR, Filén JJ, Lahesmaa R, Norman M, Neve EPA, Scheynius A, Gabrielsson S: Exosomes with immune modulatory features are present in human breast milk. J Immunol 2007, 179(3):1969-1978.

27. Hata T, Murakami K, Nakatani H, Yamamoto Y, Matsuda T, Aoki N: Isolation of bovine milk-derived microvesicles carrying mRNAs and microRNAs. Biochem Biophys Res Commun 2010, 396(2):528-533.

28. Zhou Q, Li M, Wang X, Li Q, Wang T, Zhu Q, Zhou X, Gao X, Li X: Immunerelated microRNAs are abundant in breast milk exosomes. Int J Biol Sci 2012, 8(1):118

29. Gu Y, Li M, Wang T, Liang Y, Zhong Z, Wang X, Zhou Q, Chen L, Lang Q, He $Z$, et al: Lactation-related microRNA expression profiles of porcine breast milk exosomes. PLoS One 2012, 7(8):e43691.

30. Cullen BR: RNA interference: antiviral defense and genetic tool. Nat Immunol 2002, 3(7):597-599.

31. Hutvágner $\mathrm{G}$, Zamore PD: A microRNA in a multiple-turnover RNA enzyme complex. Science 2002, 297(5589):2056-2060.

32. Carrington JC, Ambros V: Role of microRNAs in plant and animal development. Science 2003, 301(5631):336-338.

33. Cerutti $\mathrm{H}$ : RNA interference: traveling in the cell and gaining functions? Trends Genet 2003, 19(1):39-46.

34. Bartel DP: MicroRNAs: target recognition and regulatory functions. Cell 2009, 136(2):215-233.

35. Friedman RC, Farh KKH, Burge CB, Bartel DP: Most mammalian mRNAs are conserved targets of microRNAs. Genome Res 2009, 19(1):92-105.

36. Rodriguez A, Vigorito E, Clare S, Warren MV, Couttet P, Soond DR, van Dongen S, Grocock RJ, Das PP, Miska EA: Requirement of bic/microRNA155 for normal immune function. Science 2007, 316(5824):608-611.

37. Hyun $\mathrm{S}$, Lee JH, Jin H, Nam J, Namkoong B, Lee G, Chung J, Kim VN: Conserved MicroRNA miR-8/miR-200 and its target USH/FOG2 control growth by regulating PI3K. Cell 2009, 139(6):1096-1108.

38. Lal A, Navarro F, Maher CA, Maliszewski LE, Yan N, O'Day E, Chowdhury D, Dykxhoorn DM, Tsai P, Hofmann O: miR-24 Inhibits cell proliferation by targeting E2F2, MYC, and other cell-cycle genes via binding to "seedless" 3' UTR microRNA recognition elements. Mol Cell 2009, 35(5):610-625.

39. Chen CZ, Li L, Lodish HF, Bartel DP: MicroRNAs modulate hematopoietic lineage differentiation. Science 2004, 303(5654):83-86.

40. Lässer C, Alikhani VS, Ekström K, Eldh M, Paredes PT, Bossios A, Sjöstrand M, Gabrielsson S, Lötvall J, Valadi H: Human saliva, plasma and breast milk exosomes contain RNA: uptake by macrophages. J Trans/ Med 2011, 9(1):9.

41. Ji Z, Wang G, Xie Z, Wang J, Zhang C, Dong F, Chen C: Identification of novel and differentially expressed microRNAs of dairy goat mammary gland tissues using Solexa sequencing and bioinformatics. PLOS ONE 2012, 7(11):e49463.

42. Li R, Li Y, Kristiansen K, Wang J: SOAP: short oligonucleotide alignment program. Bioinformatics 2008, 24(5):713-714. 
43. Li Y, Zhang Z, Liu F, Vongsangnak W, Jing Q, Shen B: Performance comparison and evaluation of software tools for microRNA deepsequencing data analysis. Nucleic Acids Res 2012, 40(10):4298-4305.

44. Jiang P, Wu H, Wang W, Ma W, Sun X, Lu Z: MiPred: classification of real and pseudo microRNA precursors using random forest prediction model with combined features. Nucleic Acids Res 2007, 35(suppl 2):W339-W344.

45. Zuker M: Mfold web server for nucleic acid folding and hybridization prediction. Nucleic Acids Res 2003, 31(13):3406-3415.

46. Fu H, Tie $Y, X u C$, Zhang Z, Zhu J, Shi Y, Jiang H, Sun Z, Zheng X: Identification of human fetal liver miRNAs by a novel method. FEBS Lett 2005, 579(17):3849-3854

47. Kosaka N, Izumi H, Sekine $K$, Ochiya T: microRNA as a new immuneregulatory agent in breast milk. Silence 2010, 1(1):7.

48. Ebhardt HA, Fedynak A, Fahlman RP: Naturally occurring variations in sequence length creates microRNA isoforms that differ in argonaute effector complex specificity. Silence 2010, 1(1):12.

49. Guo L, Lu Z: Global expression analysis of miRNA gene cluster and family based on isomiRs from deep sequencing data. Comput Biol Chem 2010, 34(3):165-171.

50. Naya L, Khan GA, Sorin C, Hartmann C, Crespi M, Lelandais-Brière C: Cleavage of a non-conserved target by a specific miR156 isoform in root apexes of Medicago truncatula. Plant Signal Behav 2010, 5(3):328-331.

51. Li M, Xia Y, Gu Y, Zhang K, Lang Q, Chen L, Guan J, Luo Z, Chen H, Li Y: MicroRNAome of porcine pre-and postnatal development. PLoS One 2010, 5(7):e11541.

52. He L, Hannon GJ: MicroRNAs: small RNAs with a big role in gene regulation. Nat Rev Genet 2004, 5(7):522-531.

53. Lagos-Quintana M, Rauhut R, Yalcin A, Meyer J, Lendeckel W, Tuschl T: Identification of tissue-specific microRNAs from mouse. Curr Biol 2002, 12(9):735-739.

54. Tran N, O'Brien CJ, Clark J, Rose B: Potential role of micro-RNAs in head and neck tumorigenesis. Head Neck 2010, 32(8):1099-1111.

55. Morales Prieto DM, Markert UR: MicroRNAs in pregnancy. J Reprod Immunol 2011, 88(2):106-111.

56. Xie S, Huang T, Shen Y, Li X, Zhang X, Zhu M, Qin H, Zhao S: Identification and characterization of microRNAs from porcine skeletal muscle. Anim Genet 2010, 41(2):179-190.

57. Chen X, Gao C, Li H, Huang L, Sun Q, Dong Y, Tian C, Gao S, Dong H, Guan $D$ : Identification and characterization of microRNAs in raw milk during different periods of lactation, commercial fluid, and powdered milk products. Cell Res 2010, 20(10):1128-1137.

58. Ye R-S, Xi Q-Y, Qi Q, Cheng X, Chen T, Li H, Kallon S, Shu G, Wang S-B, Jiang Q-Y: Differentially Expressed miRNAs after GnRH Treatment and Their Potential Roles in FSH Regulation in Porcine Anterior Pituitary Cell. PLOS ONE 2013, 8(2):e57156.

59. Zheng B, Liang L, Wang C, Huang S, Cao X, Zha R, Liu L, Jia D, Tian Q, Wu J: MicroRNA-148a suppresses tumor cell invasion and metastasis by downregulating ROCK1 in gastric cancer. Clin Cancer Res 2011 17(24):7574-7583.

60. Zhang H, Li Y, Huang Q, Ren X, Hu H, Sheng H, Lai M: MiR-148a promotes apoptosis by targeting $\mathrm{Bcl}-2$ in colorectal cancer. Cell Death Differ 2011, 18(11):1702-1710.

61. He L, Thomson JM, Hemann MT, Hernando-Monge E, Mu D, Goodson S, Powers S, Cordon-Cardo C, Lowe SW, Hannon GJ: A microRNA polycistron as a potential human oncogene. Nature 2005, 435(7043):828-833.

62. Li L, Shi JY, Zhu GQ, Shi B: MiR-17-92 cluster regulates cell proliferation and collagen synthesis by targeting TGFB pathway in mouse palatal mesenchymal cells. J Cell Biochem 2012, 113(4):1235-1244.

63. Mendell JT: miRiad roles for the miR-17-92 cluster in development and disease. Cell 2008, 133(2):217-222.

64. Mavrakis KJ, Wolfe AL, Oricchio E, Palomero T, De Keersmaecker K, McJunkin K, Zuber J, James T, Khan AA, Leslie CS: Genome-wide RNA-mediated interference screen identifies miR-19 targets in Notch-induced T-cell acute lymphoblastic leukaemia. Nat Cell Biol 2010, 12(4):372-379.

65. Río P, Agirre X, Garate L, Baños R, Álvarez L, San José-Enériz E, Badell I, Casado JA, Garín M, Prósper F: Down-regulated expression of hsa-miR-181c in Fanconi anemia patients: implications in TNFa regulation and proliferation of hematopoietic progenitor cells. Blood 2012, 119(13):3042-3049.

66. Agrawal $R$, Tran $U$, Wessely $O$ : The miR-30 miRNA family regulates Xenopus pronephros development and targets the transcription factor Xlim1/Lhx1. Development 2009, 136(23):3927-3936.
67. Akao $Y$, Nakagawa $Y$, Naoe $T$ : let-7 microRNA functions as a potential growth suppressor in human colon cancer cells. Biol Pharm Bull 2006, 29(5):903-906.

68. Shell S, Park SM, Radjabi AR, Schickel R, Kistner EO, Jewell DA, Feig C, Lengyel E, Peter ME: Let-7 expression defines two differentiation stages of cancer. Proc Natl Acad Sci 2007, 104(27):11400-11405.

69. Ma K, He Y, Zhang H, Fei Q, Niu D, Wang D, Ding X, Xu H, Chen X, Zhu J: DNA methylation-regulated miR-193a-3p dictates resistance of hepatocellular carcinoma to 5-fluorouracil via repression of SRSF2 expression. J Biol Chem 2012, 287(8):5639-5649.

70. Kahai S, Lee SC, Lee DY, Yang J, Li M, Wang CH, Jiang Z, Zhang Y, Peng C, Yang BB: MicroRNA miR-378 regulates nephronectin expression modulating osteoblast differentiation by targeting GaINT-7. PLoS One 2009, 4(10):e7535.

71. Zhang L, Flygare J, Wong P, Lim B, Lodish HF: miR-191 regulates mouse erythroblast enucleation by down-regulating Riok3 and Mxi1. Genes Dev 2011, 25(2):119-124.

72. Schaar DG, Medina DJ, Moore DF, Strair RK, Ting Y: miR-320 targets transferrin receptor $1(\mathrm{CD} 71)$ and inhibits cell proliferation. Exp Hematol 2009, 37(2):245-255

73. Li QJ, Chau J, Ebert PJR, Sylvester G, Min H, Liu G, Braich R, Manoharan M, Soutschek J, Skare P: miR-181a is an intrinsic modulator of T cell sensitivity and selection. Cell 2007, 129(1):147-161.

74. Aslam MI, Patel M, Singh B, Jameson JS, Pringle JH: MicroRNAs are Novel Biomarkers for Detection of Colorectal Cancer. In Biomarker. Edited by Khan TK. Croatia, Rijeka: In Tech; 2012:1-18.

75. Curtis J, Bourne F: Immunoglobulin quantitation in sow serum, colostrum and milk and the serum of young pigs. Biochimica et Biophysica Acta (BBA)-Protein Structure 1971, 236(1):319-332.

76. Kumura H, Sone T, Shimazaki K, Kobayashi E: Sequence analysis of porcine polymeric immunoglobulin receptor from mammary epithelial cells present in colostrum. J Dairy Res 2000, 67(04):631-636.

77. Castigli E, Alt FW, Davidson L, Bottaro A, Mizoguchi E, Bhan AK, Geha RS CD40-deficient mice generated by recombination-activating gene-2deficient blastocyst complementation. Proc Natl Acad Sci 1994, 91(25):12135-12139.

78. Kawabe T, Naka T, Yoshida K, Tanaka T, Fujiwara H, Suematsu S, Yoshida N, Kishimoto T, Kikutani $\mathrm{H}$ : The immune responses in CD40-deficient mice: impaired immunoglobulin class switching and germinal center formation. Immunity 1994, 1(3):167.

79. Durandy A, Schiff C, Bonnefoy JY, Forveille M, Rousset F, Mazzei G, Milili M, Fischer A: Induction by anti-CD40 antibody or soluble CD40 ligand and cytokines of $\lg G, \lg A$ and $\lg E$ production by $B$ cells from patients with X-linked hyper IgM syndrome. Eur J Immunol 2005, 23(9):2294-2299.

80. Le Jan C, Chevaleyre C: Reduced expression of SLA Class 1 antigens by intestinal epithelium of newborn piglets. Vet Immunol Immunopathol 1996, 50(1):167-172.

81. Van Vlasselaer P, Punnonen J, De Vries J: Transforming growth factor-beta directs IgA switching in human B cells. J Immunol 1992, 148(7):2062-2067.

82. He B, Xu W, Santini PA, Polydorides AD, Chiu A, Estrella J, Shan M, Chadburn A, Villanacci V, Plebani A: Intestinal Bacteria Trigger T Cell-Independent Immunoglobulin A $<$ sub $>2</$ sub $>$ Class Switching by Inducing Epithelial-Cell Secretion of the Cytokine APRIL. Immunity 2007, 26(6):812-826.

83. Bowman EP, Kuklin NA, Youngman KR, Lazarus NH, Kunkel EJ, Pan J, Greenberg HB, Butcher EC: The intestinal chemokine thymus-expressed chemokine (CCL25) attracts IgA antibody-secreting cells. J Exp Med 2002, 195(2):269-275.

84. Svensson M, Marsal J, Ericsson A, Carramolino L, Brodén T, Márquez G Agace WW: CCL25 mediates the localization of recently activated CD8alphabeta^+ lymphocytes to the small-intestinal mucosa. J Clin Investig 2002, 110(8):1113-1122.

85. Lanier LL, O'Fallon S, Somoza C, Phillips JH, Linsley PS, Okumura K, Ito D, Azuma M: CD80 (B7) and CD86 (B70) provide similar costimulatory signals for $\mathrm{T}$ cell proliferation, cytokine production, and generation of CTL. J Immunol 1995, 154(1):97-105.

86. Hutloff A, Dittrich AM, Beier KC, Eljaschewitsch B, Kraft R, Anagnostopoulos I, Kroczek RA: ICOS is an inducible T-cell co-stimulator structurally and functionally related to CD28. Nature 1999, 402:21-24.

doi:10.1186/1471-2164-15-100

Cite this article as: Chen et al:: Exploration of microRNAs in porcine milk exosomes. BMC Genomics 2014 15:100. 